\title{
Diurnal Circulation Adjustment and Organized Deep Convection
}

\author{
JAMES H. RUPPERT JR. AND CATHY HOHENEGGER \\ Max Planck Institute for Meteorology, Hamburg, Germany
}

(Manuscript received 14 October 2017, in final form 13 March 2018)

\begin{abstract}
This study investigates the diurnal cycle of tropical organized deep convection and the feedback in largescale circulation. By considering gravity wave phase speeds, we find that the circulation adjustment into weak temperature gradient (WTG) balance occurs rapidly $(<6 \mathrm{~h})$ relative to diurnal diabatic forcing on the spatial scales typical of organized convection $(\leq 500 \mathrm{~km})$. Convection-permitting numerical simulations of selfaggregation in diurnal radiative-convective equilibrium (RCE) are conducted to explore this further. These simulations depict a pronounced diurnal cycle of circulation linked to organized convection, which indeed maintains WTG balance to first order. A set of sensitivity experiments is conducted to assess what governs the diurnal cycle of organized convection. We find that the "direct radiation-convection interaction" (or lapserate) mechanism is of primary importance for diurnal precipitation range, while the "dynamic cloudy-clear differential radiation" mechanism amplifies the range by approximately $30 \%$, and delays the nocturnal precipitation peak by around $5 \mathrm{~h}$. The differential radiation mechanism therefore explains the tendency for tropical heavy rainfall to peak in the early morning, while the lapse-rate mechanism primarily governs diurnal amplitude. The diurnal evolution of circulation can be understood as follows. While nocturnal deep convection invigorated by cloud-top cooling (i.e., the lapse-rate mechanism) leads to strong bottom-heavy circulation at nighttime, the localized (i.e., differential) top-heavy shortwave warming in the convective region invigorates circulation at upper levels in daytime. A diurnal evolution of the circulation therefore arises, from bottom heavy at nighttime to top heavy in daytime, in a qualitatively consistent manner with the observed diurnal pulsing of the Hadley cell driven by the ITCZ.
\end{abstract}

\section{Introduction}

As a leading mode of climate variability, the diurnal cycle serves as a critical test of validation for both numerical weather prediction and global climate models (Yang and Slingo 2001; Dai and Trenberth 2004; Dai 2006; Pritchard and Somerville 2009). Even subtle model errors on this time scale may lead to substantial biases at longer time scales, owing to nonlinear rectification by diurnal processes. Such rectification can arise, for example, through diurnally modulated moist convection (Ruppert 2016; Ruppert and Johnson 2016), the upper-ocean convective mixing cycle (Webster et al. 1996; Bernie et al. 2005; Matthews et al. 2014), or diurnal island-atmosphere and air-sea interaction (Neale and Slingo 2003; Peatman et al. 2014; Ruppert and Johnson 2015; Cronin et al. 2015). While addressing model deficiencies related to the diurnal cycle is therefore critical,

Corresponding author: James H. Ruppert Jr., james.ruppert@ mpimet.mpg.de open questions on the underlying dynamics hinder such efforts.

This study investigates the diurnal cycle in organized tropical deep convection, the governing dynamics of which have withstood decades of deliberation (Kraus 1963; Gray and Jacobson 1977; Dudhia 1989; Randall et al. 1991; Chen and Houze 1997). There is mounting evidence of a pronounced diurnal cycle in tropical cyclones, as observed both in cirrus outflow characteristics (Kossin 2002; Dunion et al. 2014) and precipitation (Bowman and Fowler 2015). This diurnal cycle is linked to changes in the shape of the vertical mass flux profile, which in turn impacts spinup of the cyclone's primary circulation (Davis and Ahijevych 2012; Melhauser and Zhang 2014; Nicholls 2015). Similarly, observations reveal a characteristic diurnal cycle of deep convection in the ITCZ, which drives a diurnal pulsing of the Hadley cell (Deser and Smith 1998; Bain et al. 2010; Ciesielski et al. 2018).

To explain diurnal cycles in large-scale circulation, hypotheses have been advanced that invoke mechanisms of the diurnal cycle in convection; however, we lack a 
basic understanding of circulation dynamics on this time scale. Furthermore, the literature reveals a lack of consensus on what mechanisms govern the diurnal cycle of organized convection in this regime (Yang and Smith 2006; Johnson 2011) (section 2b). This study aims to address these two gaps through theoretical considerations of tropical circulation dynamics and numerical model experiments, which will be conducted in an idealized framework to better disentangle the effects of convection and radiation on large-scale circulation.

First, to understand the dynamics of convectioncirculation interaction in the diurnal cycle, the weak temperature gradient (WTG) approximation is invoked (Sobel et al. 2001). While a justifiable a priori assumption is that WTG balance is inapplicable on such time scales (Yano and Bonazzola 2009), an argument to the contrary is put forth in this study through consideration of gravity wave phase speeds and the time scales of WTG balance adjustment.

Second, to further investigate diurnal convectioncirculation interaction, we invoke the idealized numerical modeling approach of self-aggregation in diurnal radiative-convective equilibrium (RCE). Much has been learned from self-aggregation concerning the manners in which moist convection and circulation grow upscale, and the role of cloud-radiation interaction, humidity-longwave interaction, and surface fluxes in this upscale growth (Tompkins and Craig 1998; Bretherton et al. 2005; Muller and Held 2012; Emanuel et al. 2014; Wing and Emanuel 2014; Holloway et al. 2017; Naumann et al. 2017; Wing et al. 2017). Yet very few studies of self-aggregation have included a diurnal cycle (Hohenegger and Stevens 2016; Wing and Cronin 2016), while none to date have analyzed it in this framework. This gap is addressed here, where we exploit the RCE self-aggregation framework to investigate the diurnal cycle in both disorganized and organized states of convection. These simulations will demonstrate the important impact of diurnal variations in shortwave heating on large-scale circulation, in addition to its impacts on deep convection and precipitation.

In summary, this study aims to improve our understanding of the diurnal cycle in large-scale circulation by identifying the specific mechanisms governing the diurnal cycle of organized tropical deep convection. WTG theory and the time scales of WTG balance adjustment are discussed in section $2 \mathrm{a}$, followed by a review of the pertinent diurnal cycle mechanisms considered in this specific context (section 2b). Next are the methodology for the modeling study (section 3), the modeling study results (section 4), and conclusions (section 5).

\section{WTG balance and the diurnal cycle}

\section{a. WTG balance adjustment}

The large-scale heat budget is encompassed by the apparent heat source $Q_{1}$ of Yanai et al. (1973):

$$
Q_{1} \equiv \frac{\partial \bar{s}}{\partial t}+\overline{\mathbf{v}} \cdot \nabla \bar{s}+\bar{w} \frac{\partial \bar{s}}{\partial z}=Q_{R}+Q_{c}
$$

where $s=c_{p} T+g z$ is dry static energy; $\mathbf{v}$ is horizontal velocity; $w$ is vertical wind, $Q_{R}$ is total radiative heating; $Q_{c}$ is total convective heating, the sum of vertical eddy heat flux convergence and microphysical heating (e.g., Johnson et al. 2016); $c_{p}$ is the specific heat of dry air at constant pressure; $T$ is temperature; and $g$ is gravity. Overbars denote horizontal averaging across an ensemble of convective elements, and $Q_{c}$ is calculated as $Q_{c}=Q_{1}-Q_{R}$.

In contrast to midlatitudes, where quasigeostrophic motions can sustain strong large-scale horizontal temperature gradients, the tropics are characterized by a lack of geostrophic balance, and hence very weak temperature gradients (Charney 1963). Tropical thermodynamics may therefore be described to first order by

$$
\frac{\partial \bar{s}}{\partial t}+\bar{w} \frac{\partial \bar{s}}{\partial z} \approx Q_{1},
$$

the solution to which is a gravity wave. Therefore, instead of horizontal advection, the prevailing mechanism for large-scale horizontal temperature adjustment is the rapid spreading and homogenization of buoyancy anomalies by gravity waves (Bretherton and Smolarkiewicz 1989; Nicholls et al. 1991; Mapes 1993). Gravity waves act by adjusting vertical circulation, which modulates temperature through adiabatic compression and expansion of the statically stable free troposphere. ${ }^{1}$

On time scales far exceeding those of gravity wave adjustment, the time-tendency term vanishes, and a balance arises, which is referred to as WTG balance (Sobel and Bretherton 2000; Sobel et al. 2001):

$$
\bar{w} \frac{\partial \bar{s}}{\partial z} \approx Q_{1} .
$$

Thus, when gravity waves have done their job of homogenizing buoyancy, a balance arises between adiabatic cooling and warming (left-hand side) and diabatic heat sources and sinks (right-hand side). Observations demonstrate that WTG balance prevails quite generally

\footnotetext{
${ }^{1}$ While $s$ is shown here for consistency with the literature, gravity waves in fact respond to localized buoyancy anomalies manifest in virtual (or density) potential temperature.
} 


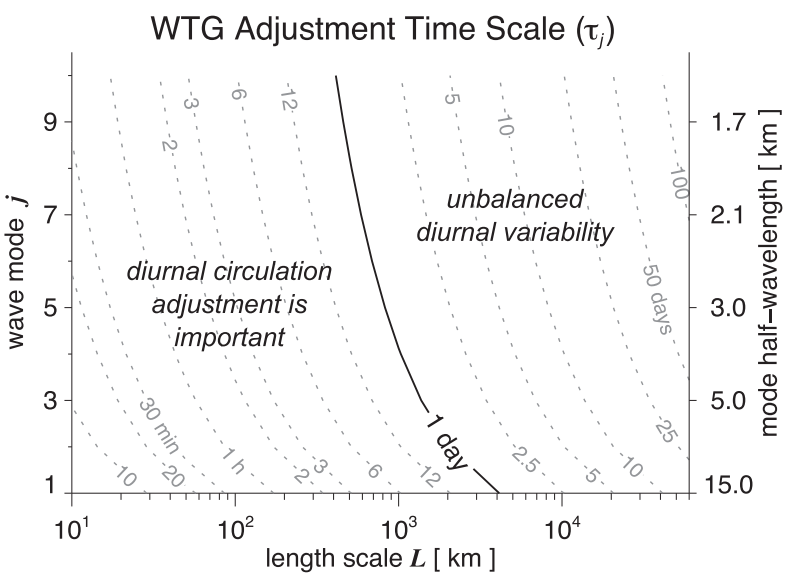

FIG. 1. The time scale $\tau_{j}$ at which WTG balance hypothetically applies, as a function of hydrostatic gravity wave mode $j$ and adjustment length scale $L(\mathrm{~km})$. The corresponding mode halfwavelength $(\mathrm{km})$, calculated as $h / j$, is indicated on the right-hand $y$ axis.

in the tropics, on time scales of several days and greater, and from the mesoscale up to large-scale equatorial waves such as the Madden-Julian oscillation (MJO) (Yano and Bonazzola 2009; Chikira 2014; Wolding et al. 2016).

The question of whether WTG balance applies to the diurnal cycle requires special consideration. Time variations of temperature over $24 \mathrm{~h}$ as measured by soundings, for example, are typically of $O(1) \mathrm{K}$ in magnitude [Fig. 4b of Ruppert (2016)]. Such rapid temperature variations manifest in large magnitude of the local timetendency term in Eq. (2), giving the impression that WTG balance is inapplicable to the diurnal cycle (Yano and Bonazzola 2009); however, this is a false impression.

To understand the applicability of WTG theory to the diurnal cycle, we must first understand the time scales of the WTG balance-adjustment process. As noted earlier, balance adjustment is achieved by gravity waves, following Eq. (2). The lower limit on the adjustment time scales is therefore set by the propagation rate of gravity waves; or more specifically, the time required for gravity waves to propagate over a distance $L$, the horizontal scale of an assumed circulation system. Once they have done so, we assume that the associated buoyancy anomaly is homogenized and WTG balance is restored, to first order.

Following Herman and Raymond (2014), we assume a series of hydrostatic modes with horizontal phase speed $c_{j}=N h / j \pi$, where $N \sim 0.01 \mathrm{~s}^{-1}$ is static stability, $h \sim$ $15 \mathrm{~km}$ is troposphere depth, and $j=1,2,3, \ldots$ is the wave mode. The time scale of balance adjustment (or its lower limit, strictly speaking) is then $\tau_{j}=L / c_{j}$. Figure 1 depicts $\tau_{j}$ calculated for a range of $L$ and $j$. The value of $\tau_{j}$ increases systematically with $L$, with the 1-day contour situated at $L=4000 \mathrm{~km}$ for the first baroclinic mode. The value of $\tau_{j}$ also increases with $j$ because of the decrease of $c_{j}$ with $j$.

We may therefore take $L_{\mathrm{dc}} \sim 10^{3} \mathrm{~km}$ (roughly $10^{\circ}$ of longitude or latitude) as a hypothetical upper limit for diurnal-WTG balance. Tropical cloud clusters, such as mesoscale convective systems (MCSs) and tropical cyclones, are typically of a scale well below $L_{\mathrm{dc}}$ (Mapes and Houze 1993). Circulation adjustment toward WTG balance is therefore likely an important process in such systems.

This argument does not rule out the potential importance of transient, small-amplitude buoyancy anomalies for convective activity, however. Indeed, for diurnal forcing on scales $L>L_{\mathrm{dc}}$, balance adjustment is a slow process relative to the diurnal cycle. For example, if daytime shortwave warming and nocturnal cooling manifest on a scale of $O\left(10^{4}\right) \mathrm{km}$ at a given instant (i.e., on a hemispheric scale), it takes 2.5 days for the first gravity wave mode to cover such a distance, and longer for higher modes (Fig. 1). Therefore, gravity waves cannot keep up with diurnal diabatic forcing on this very large spatial scale, yielding

$$
\left\langle\frac{\partial \bar{s}}{\partial t}\right\rangle \approx\left\langle Q_{1}\right\rangle,
$$

where angle brackets denote averaging on scales of $L \gg L_{\mathrm{dc}}$. Large-magnitude diurnal temperature variations in observations (Ruppert 2016) are evidence of this very large-scale, unbalanced diurnal temperature fluctuation. Therefore, balance may exist at smaller scales, with large-magnitude, unbalanced variations superposed at much larger scales.

These arguments provide a new basis for the mechanisms proposed in the literature to explain the diurnal cycle of deep convection over open ocean, which are discussed next.

\section{b. Review of mechanisms}

The diurnal cycle of precipitation over the tropical open oceans is characterized by two peaks: a robust peak overnight-early morning linked to heavy rainfall in organized deep-convective systems, and a weaker peak in the afternoon characteristic of more suppressed conditions (Gray and Jacobson 1977; Mapes and Houze 1993; Chen and Houze 1997; Sui et al. 1997; Wood et al. 2002; Nesbitt and Zipser 2003; Yang and Smith 2006; Kikuchi and Wang 2008). Neither of these peaks require the remote influences from land or solar tides to explain, although these mechanisms can certainly be important (Woolnough et al. 2004; Yang and Smith 2006). 
The weaker afternoon peak in tropical rainfall is the result of daytime convective invigoration by largeamplitude diurnal sea surface temperature (SST) variations, which typically reach approximately $2 \mathrm{~K}$ in suppressed conditions characterized by shallow convection (Chen and Houze 1997; Sui et al. 1997; Johnson et al. 2001; Bellenger et al. 2010; Ruppert and Johnson 2015; Johnson and Ciesielski 2017). This afternoon mechanism has been investigated in past studies, and is hence not treated here (Bellenger et al. 2010; Ruppert and Johnson 2015, 2016).

The focus of this study is on the dominant overnightearly-morning peak. This peak is linked to heavy rainfall in organized deep convection (Gray and Jacobson 1977), such as in MCSs (Mapes and Houze 1993; Chen and Houze 1997; Nesbitt and Zipser 2003), tropical cyclones (Bowman and Fowler 2015), the ITCZ (Ciesielski et al. 2018), and other large-scale convergence zones (Deser and Smith 1998; Kikuchi and Wang 2008; Bain et al. 2010). There are two well-supported theories for this nocturnal precipitation enhancement, both of which invoke diurnal variations in radiative heating and its interaction with deep convection. For much broader reviews, see Yang and Smith (2006), Johnson (2011), and Nicholls (2015).

The "direct radiation-convection interaction" mechanism (or simply, the lapse-rate mechanism) invokes a one-dimensional argument that emphasizes diurnal changes in lapse rate or static stability resulting from diurnal radiative heating in deep convection. Specifically, shortwave absorption by upper-level clouds (Webster and Stephens 1980) results in a top-heavy daytime cloudradiative forcing (CRF) structure with upper-level warming in convective regions, which in turn stabilizes the column and suppresses moist convection (Kraus 1963; Randall et al. 1991; Xu and Randall 1995; Liu and Moncrieff 1998). At night, shortwave warming is absent, and convective activity is enhanced in association with the upper-level cooling because of longwave emission from cloud tops [the diurnal cycle of $Q_{R}$ and CRF in deep convection is depicted in Fig. 17 of Ciesielski et al. (2018)]. Diurnal changes in the vertical profile of temperature are consistent with the lapse-rate mechanism, as found in both observations (Ruppert 2016) and models (Randall et al. 1991; Xu and Randall 1995; Liu and Moncrieff 1998). Specifically, temperature exhibits warm diurnal anomalies in the afternoon that increase in amplitude with height through the cloud layer, and cool anomalies overnight-early morning that similarly increase with height. These temperature anomalies maximize around the level of cloud top, that is, $12-15 \mathrm{~km}$ in deep convection [Fig. 9 of Randall et al. (1991)], and 4-7 km in congestus convection [Fig. 4b of Ruppert (2016)].
There has been more disagreement, however, regarding the importance of the "dynamic cloudy-clear differential radiation" mechanism proposed in the observational studies of Ruprecht and Gray (1976) and Gray and Jacobson (1977). According to this hypothesis, the diurnal variation of $Q_{R}$ within an organized convective system is weak because of the presence of clouds, while in the cloud-free region, subsidence is nocturnally enhanced by strong radiative cooling, and suppressed during the day with reduced cooling. Through mass continuity between the cloud-free and convective regions, ascending motion is enhanced in the convective region at night, and reduced during the day, leading to a nocturnal peak in convective activity.

A key assumption of Gray and Jacobson (1977) is that lapse rate and temperature do not change much, therefore implying WTG balance, following from which are the dynamic arguments encompassed by their hypothesis. As discussed in section 2a, WTG balance adjustment occurs rapidly relative to the diurnal cycle on scales typical of organized convection (Fig. 1). In this sense, the assumption of Gray and Jacobson (1977) is valid, and diurnal changes in differential radiation should therefore drive circulation changes. Nevertheless, unbalanced diurnal temperature fluctuations likely manifest on much larger spatial scales (Randall et al. 1991; Xu and Randall 1995; Ruppert 2016) in accordance with Eq. (4).

Many prior studies, claiming that the differential radiation mechanism is a small-order effect, have important caveats. Randall et al. (1991) conducted global model simulations on a grid of approximately $500-\mathrm{km}$ spacing. This grid was inadequate to resolve convection, although parameterized convection responded diurnally to unbalanced temperature fluctuations manifesting on very large scales, and the associated changes in lapse rate. While convection was explicitly simulated in several other studies, these were conducted in only two dimensions, which inherently limits the dynamic response to diurnal diabatic forcing (Dudhia 1989; Tao et al. 1996; Liu and Moncrieff 1998). Furthermore, only highly transient convection in the form of fast squall lines was treated, where circulation balance is likely inapplicable. In a recent study by Nicholls (2015), the differential radiation mechanism was indeed argued to be highly important in three-dimensional simulations of a developing tropical cyclone, consistent with the arguments presented in section 2a. The present study will build upon the findings of Nicholls (2015) by comparing convection in organized and disorganized states, and exploring mechanisms of the diurnal cycle in the context of organized convection in nonrotating RCE. 
Motivated by the above discussion, a new hypothesis is posed in this study - that diurnal changes in both lapse rate and differential radiative heating are critical to the diurnal cycle of organized tropical deep convection. This study will provide evidence through numerical model simulations of how both diurnal mechanisms indeed cooperate in organized convection. The results will additionally demonstrate the high degree to which circulation maintains approximate WTG balance owing to rapid circulation adjustment.

\section{Modeling methodology}

Model simulations are conducted with the Icosahedral Nonhydrostatic (ICON) model, developed jointly by the Max Planck Institute for Meteorology and the German Weather Service (DWD). ICON was developed as a unified model, catering to applications ranging from climate prediction down to large-eddy modeling (LEM). ICON employs a geodesic Delaunay (triangular) grid system, with C-type staggering. The prognostic variables are virtual potential temperature $\theta_{v}, w$, density, triangle edge-normal horizontal velocity, and the specific masses and number densities of water vapor and condensate. The dynamics are described in more detail by Zängl et al. (2015), while implementation of the LEM framework is described by Dipankar et al. (2015).

For the LEM framework employed in this study, a simplified flat geometry is assumed on a doubly periodic domain of $(900 \mathrm{~km})^{2}$, made up of triangles of 3-km edge length. Earth's rotation is excluded. A Smagorinsky turbulence scheme is employed that accounts for thermal stratification (Dipankar et al. 2015). Also employed are the two-moment microphysics scheme of Seifert and Beheng (2006), and the Rapid Radiative Transfer Model (RRTM) scheme (Mlawer et al. 1997; Clough et al. 2005; Iacono et al. 2008). Solar zenith angle is calculated assuming a latitude of $19.5^{\circ} \mathrm{N}$ with equinox conditions, and including the diurnal cycle, which is the same at all columns. This zenith angle yields daily mean top-of-atmosphere insolation of $413.6 \mathrm{~W} \mathrm{~m}^{-2}$, which approximates the annual mean at the equator (Wing and Cronin 2016). $\mathrm{CO}_{2}$ volume mixing ratio is fixed to $348 \mathrm{ppm}$. Ozone is prescribed using a fixed vertical profile following Popke et al. (2013). Surface fluxes are calculated interactively from the bulkaerodynamic formulae assuming the drag-law formulation (Dipankar et al. 2015), with fixed sea surface temperature of $300 \mathrm{~K}$.

The model is discretized in the vertical using a stretched grid of 75 vertical levels, with spacing increasing smoothly from $30 \mathrm{~m}$ near the surface to around $700 \mathrm{~m}$ near model top $(27 \mathrm{~km})$. A sponge layer is implemented from $19 \mathrm{~km}$ and above using the Klemp et al. (2008) scheme in which only vertical motion is damped.

Similar to the procedure of Bretherton et al. (2005), model output is coarsened by interpolation onto a regular Cartesian grid of approximately $(75 \mathrm{~km})^{2}$ spacing, yielding 144 new grid cells. Each new grid cell represents averages across approximately 600 native model grid cells, such that convective motions are averaged out and only mesoscale motion is retained. This interpolation is conducted with the first-order conservative remapping function remapycon of the Climate Data Operators (CDO) software (version 1.9; https://code.mpimet.mpg. de/projects/cdo). Analysis will invoke model output both on this new coarser grid and on the native grid. All analysis is conducted with hourly model output.

\section{RCE model framework}

Similar to past studies of self-aggregation, temperature and humidity profiles used to initiate the model are generated from a preliminary simulation conducted with the identical model framework, but on a smaller domain of $(150 \mathrm{~km})^{2}$ where RCE is achieved without aggregation (Muller and Held 2012; Wing and Emanuel 2014; Wing and Cronin 2016). These profiles are taken from space and time averages over 70-90 days of the smalldomain simulation. Small-amplitude noise of $\leq|0.3| \mathrm{K}$ and $\leq|0.1| \mathrm{m} \mathrm{s}^{-1}$ is added to $\theta_{v}$ and $w$, respectively, in the lowest three model levels of the initial state to break symmetry. The initial profile has no wind. With this RCE initialization procedure, the primary largedomain simulation exhibits little mean change until selfaggregation begins.

The primary large-domain simulation (CTL) is initialized as described above, and integrated for 90 days. This simulation is characterized by an approximate 10-day period of scattered deep convection, followed by the self-aggregation of convection into one singular, stationary system by 40 days (Fig. 2). CTL is employed to investigate the diurnal cycle of convection and circulation in both disorganized and organized periods. Several sensitivity simulations are conducted to isolate the relative impact of the diurnal cycle mechanisms in both disorganized and organized convection. These simulations are described in the main text alongside the results.

\section{Results}

The results section is composed as follows. Provided first is an overview of self-aggregation in CTL (section 4a). Next, the diurnal cycle of convection in CTL is described in detail in both disorganized and organized states, with emphasis on identifying the relationships between $Q_{R}, Q_{c}$, 
(a) Histogram of Precipitable Water
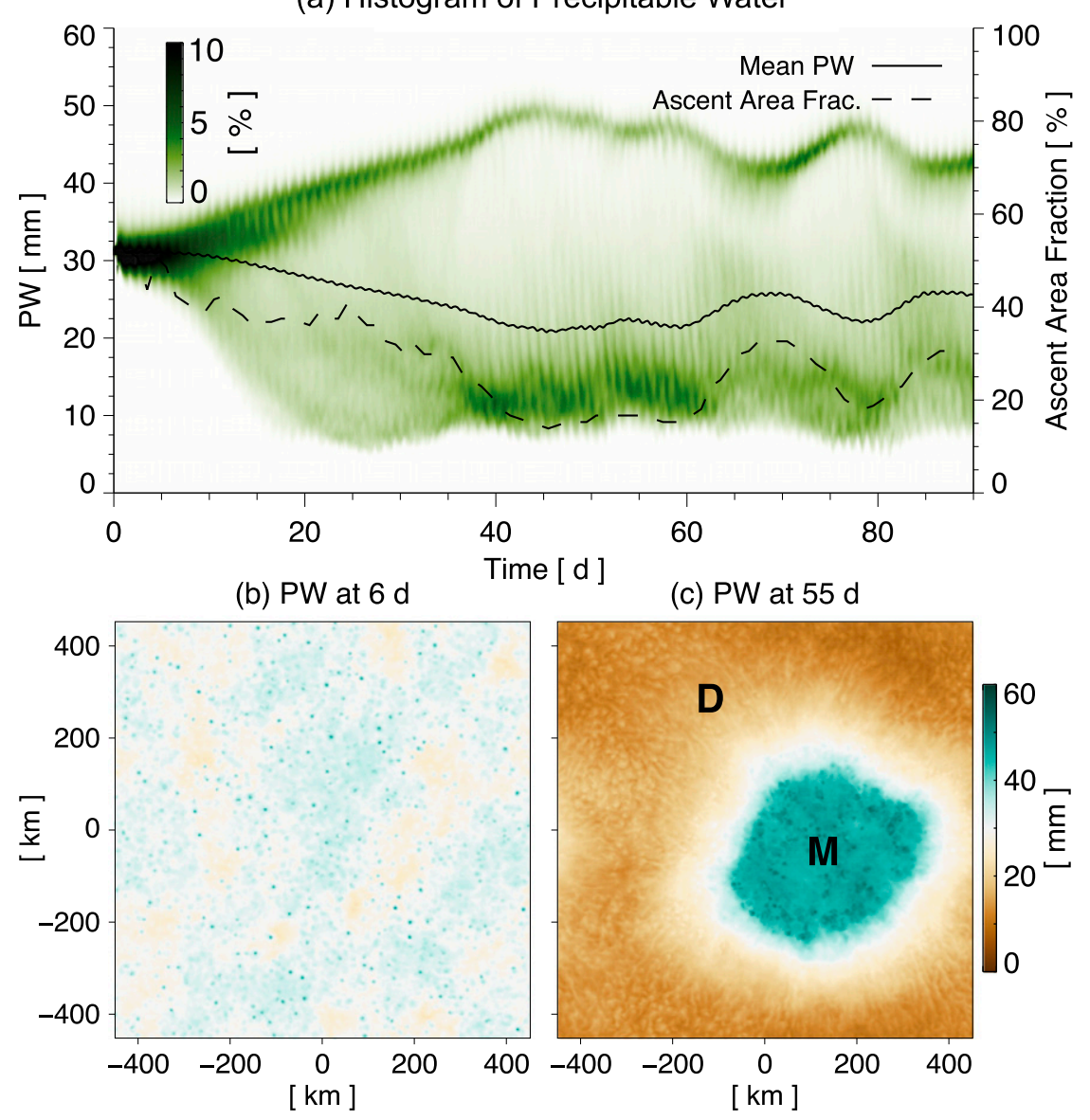

FIG. 2. (a) Histogram of PW (shaded; \% of grid cells), domain-mean PW (solid), and domain area fraction of column-integrated ascending motion (dashed) in CTL. Maps of PW at (b) 6 and (c) 55 days. The letters $M$ and D refer to the moist patch (convective region) and dry region, respectively, distinguished by areas of upward and downward column-integrated mass flux on the $75-\mathrm{km}$ grid (dividing point is situated approximately at the $30-\mathrm{mm}$ contour in PW, and is indicated by crosses in Fig. 7). PW variables are from the native model grid, while ascent area fraction is calculated from the coarsened $(75 \mathrm{~km})$ grid and smoothed with a 3 -day running average.

and diurnal circulation changes and the validity of the WTG approximation (section 4b). Described last is a set of sensitivity simulations conducted to quantify the relative role of diurnal changes in lapse rate and differential radiation (section 4c).

\section{a. Self-aggregation in CTL}

The occurrence of self-aggregation in CTL is depicted by the time-evolving histogram of precipitable water (PW; Fig. 2a). Beginning from the homogeneous initial state with PW around $30 \mathrm{~mm}$, a widening of the histogram is clear by 10 days. While the dry and moist extremes both intensify, the domain-mean PW decreases, as noted in prior RCE studies (Bretherton et al. 2005; Muller and Held 2012; Wing and Emanuel 2014; Muller and Bony 2015; Hohenegger and Stevens 2016; Wing et al. 2017). This domain-mean drying is associated with the expansion of dry regions, which leads to an aggregation of humid regions and convective activity (Wing and Emanuel 2014; Hohenegger and Stevens 2016). Expansion of the dry subsiding regions is demonstrated by the decreasing area fraction of column-integrated ascending motion (Fig. 2a). Area fraction reaches a minimum of about $20 \%$ and persists there from 40 to 60 days, which is reflected in the PW histogram by increased frequencies in the dry extreme.

In the horizontal plane, PW exhibits weak variance at 6 days, with convective cells, visible as small points of increased PW, randomly distributed throughout the domain (Fig. 2b). The pattern at 55 days, in contrast, 
TABLE 1. Mean and diurnal amplitude of domain-mean precipitation (second column; $\mathrm{mm} \mathrm{day}^{-1}$; in parentheses the percentage of the mean), that averaged over the moist patch M (third column), and area fraction of M (fourth column) for each simulation. Sampling periods are 2-9 days for CTL (disorganized), 50-59 days for CTL (organized), 2-9 days for H-RAD, and 10-19 days for P-RAD, DC-MPATCH, and HRAD-MPATCH (date ranges are inclusive). Amplitude is calculated by subtracting daily mean values, then compositing and taking half the difference between maximum and minimum composite values (and as a percentage of the sample-period mean).

\begin{tabular}{lccc}
\hline \hline \multicolumn{1}{c}{ Simulation } & Mean and diurnal amplitude $(\%)$ & Averaged over M & Area fraction of M \\
\hline CTL (disorganized) & 2.65 and $0.94(35.5)$ & 3.59 and $1.13(31.5)$ & $43.1 \%$ \\
CTL (organized) & 3.20 and $1.22(38.2)$ & 19.1 and $7.33(38.3)$ & $16.7 \%$ \\
H-RAD & 2.65 and $0.91(34.4)$ & 2.67 and $0.92(34.5)$ & $52.1 \%$ \\
P-RAD & 3.28 and $1.73(52.8)$ & 15.5 and $8.30(53.6)$ & $20.1 \%$ \\
DC-MPATCH & 3.27 and $1.14(35.0)$ & 16.3 and $6.04(37.0)$ & $19.4 \%$ \\
HRAD-MPATCH & 3.28 and $1.26(38.5)$ & 19.0 and $7.41(39.0)$ & $16.7 \%$ \\
\hline
\end{tabular}

indicates a high degree of organization, with deep convection in the moist patch $(\mathrm{M})$ and subsidence in the surrounding dry region (D) (Fig. 2c). This pattern exemplifies the quasi-stationary system that persists from around 35 days to the end of the simulation. This system is of scale $L \sim 500 \mathrm{~km}$. Although this scale is sensitive to the domain size (Muller and Held 2012; Wing and Cronin 2016), it approximates organized convection as it occurs in nature (Mapes and Houze 1993; Chen and Houze 1997).

Prior RCE studies have indicated a number of feedback processes that can cause self-aggregation, which relate to cloud-radiation interaction, longwave-water vapor interaction, and interactive surface fluxes (Tompkins and Craig 1998; Bretherton et al. 2005; Muller and Held 2012; Emanuel et al. 2014). Mounting evidence points to the particular importance of a cloudlongwave instability mechanism for driving self-aggregation, whereby enhanced radiative cooling from the boundary layer and shallow clouds in slightly drier regions increases local subsidence, both amplifying the spatial differences and expanding the dry regions (Muller and Held 2012; Wing and Emanuel 2014; Muller and Bony 2015; Hohenegger and Stevens 2016; Wing and Cronin 2016; Naumann et al. 2017; Wing et al. 2017).

\section{b. The diurnal cycle in CTL}

Henceforth in the study, the disorganized period will refer to the period from 2 to 9 days (inclusive) in CTL, while the organized period will refer to the period from 50 to 59 days (Fig. 2). This distinction is based on the narrow distribution of PW in the early period, as compared to later times, which is associated with widespread convection.

Mean- and diurnal-amplitude values of domainaveraged and $\mathrm{M}$-averaged precipitation are provided in Table 1 for each simulation, while the diurnal cycle of domain-averaged precipitation for these two periods is depicted through composites in Fig. 3a (sensitivity simulations are discussed in section 4c). Domain- and time-mean precipitation is $3.2 \mathrm{~mm} \mathrm{day}^{-1}$ in the organized period, compared to $2.65 \mathrm{~mm} \mathrm{day}^{-1}$ in the disorganized period. While the $\mathrm{M}$-averaged values are similar to the domain-averaged values in the disorganized period, since precipitation is randomly distributed throughout the domain, precipitation is almost fully confined to the moist region $\mathrm{M}$ in the organized period. Separation of the standard deviation bars between the diurnal extrema indicates that they are statistically significant.

Peak and minimum are at 0400 and 1700 local time (LT) in the disorganized period, with very little day-today variability in this diurnal cycle. The diurnal cycle in the organized period is greater in amplitude by about $0.3 \mathrm{~mm} \mathrm{day}^{-1}$ (Table 1), and is characterized by much greater day-to-day variability. The amplitude difference is mainly caused by a higher maximum in the organizedperiod composite, as minima are similar. The diurnal cycle in the organized period is also shifted earlier in phase by $2 \mathrm{~h}$, with peak and minimum at 0200 and $1400 \mathrm{LT}$. While the large day-to-day variability in the composite implies possible variability in the timing of the peak, separation between standard deviation bars indicates that the amplitude and phase differences between the two periods are significant.

Observations over the open ocean suggest a peak in precipitation around 0600 LT (Gray and Jacobson 1977; Sui et al. 1997; Kikuchi and Wang 2008; Yang et al. 2008). The timing of peak simulated precipitation in CTL is $2-4 \mathrm{~h}$ earlier than that depicted in observations. While the cause of this time bias is unknown, one hypothesis is that it relates to the idealized nature of the model framework employed here. Specifically, diurnal tides and equatorial waves are both neglected, both of which may be important to the phasing of the diurnal cycle in nature (Chen and Houze 1997; Woolnough et al. 2004). Despite this time bias, the simulation adequately simulates the nocturnal intensification of deep 


\section{Diurnal Cycle of Precipitation}
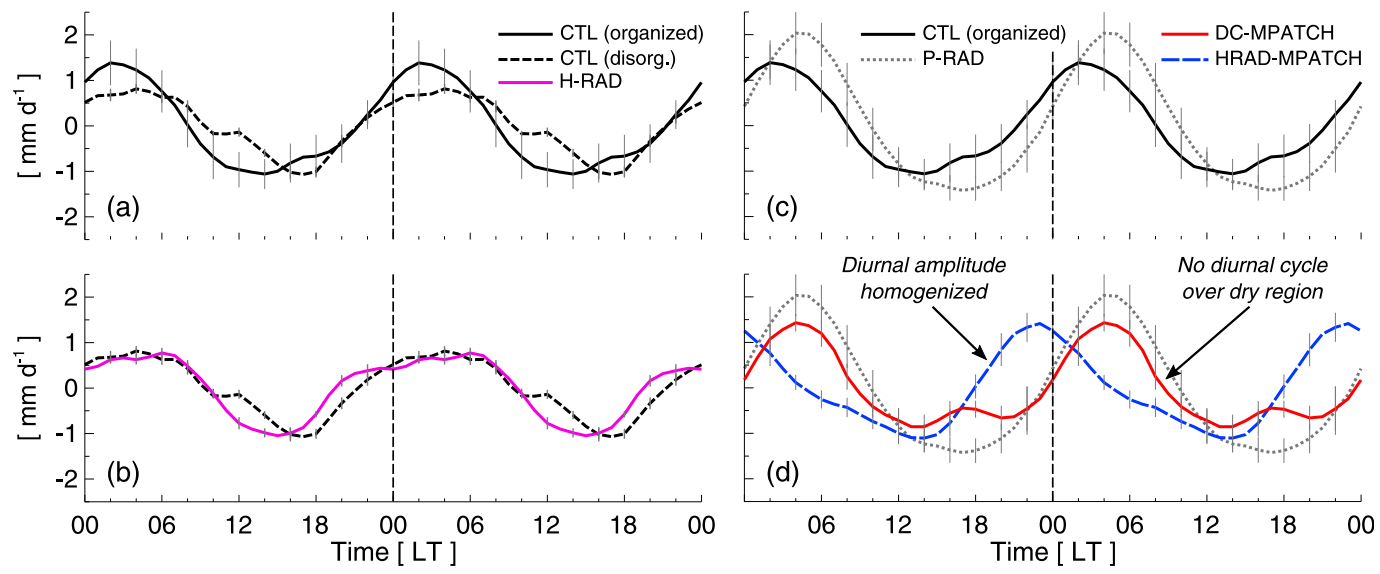

FIG. 3. Diurnal composites of domain-mean precipitation with sample means removed, repeated for detail. The vertical bars indicate the sample standard deviation (i.e., day-to-day variability) for a given hour. (a) CTL (disorganized period; dashed) and CTL (organized period; solid); (b) CTL (disorganized period; dashed) and H-RAD (magenta); (c) CTL (organized period; solid) and P-RAD (dotted); and (d) P-RAD (dotted), DC-MPATCH (red solid), and HRAD-MPATCH (blue dashed). See Table 1 for mean- and diurnal-amplitude values and composite time periods. The sensitivity simulations H-RAD, P-RAD, HRAD-MPATCH, and DC-MPATCH are described in section $4 \mathrm{c}$.

convection in response to cloud-radiation interaction, as in nature.

The diurnal cycle of convection and circulation cannot be completely understood without assessing both $Q_{R}$ and $Q_{c}$, as will be demonstrated later. Since $Q_{R}$ is the fundamental impetus for diurnal changes in convection and circulation, however, the radiative forcing is described first-namely, diurnal lapse-rate changes resulting from top-heavy shortwave CRF, and diurnal variations in differential $Q_{R}$, which relate to the dynamic cloudy-clear differential radiation mechanism.

To identify diurnal lapse-rate changes in CTL, the diurnal cycle of horizontally averaged $\theta_{v}^{*}$, that is, the deviation of $\theta_{v}$ from the daily mean, is shown in both the disorganized and organized periods (Fig. 4). Since the horizontal average of $w$ must be zero for mass conservation in the model domain, Eq. (4) is strictly obeyed in the domain mean. In consequence, changes in domain-mean temperature arise, which cannot be offset by circulation changes (i.e., the differential radiation mechanism), although they can modulate convective activity (via the lapse-rate mechanism). In the disorganized period, the diurnal range of $\theta_{v}^{*}$ is approximately $0.3 \mathrm{~K}$ in the lower troposphere and $0.6 \mathrm{~K}$ in the upper troposphere, with an evolution qualitatively resembling that in prior studies (Randall et al. 1991; Liu and Moncrieff 1998). During the organized period, the diurnal range is lower in magnitude in the free troposphere, and is greater in the boundary layer. To understand this difference between the organized and disorganized period, $Q_{R}$ is depicted for the organized period averaged over the dry and moist regions $\mathrm{D}$ and $\mathrm{M}$ (Fig. 5). Comparison of $Q_{R}$ between $\mathrm{D}$ and $\mathrm{M}$ indicates that diurnal $Q_{R}$ variations in the free troposphere are substantially greater in magnitude in $\mathrm{M}$ because of greater midday shortwave warming, while they are greater in the PBL in D because of greater nocturnal cooling. Enhanced $Q_{R}$ cooling in the PBL of D owes to the dry, cloud-free conditions above the PBL, given that subsidence prevails. In $\mathrm{M}$, a moister, cloudier troposphere leads to greater shortwave absorption through much of the troposphere, while reducing the magnitude of PBL cooling. The pattern of $\theta_{v}^{*}$ in the organized period

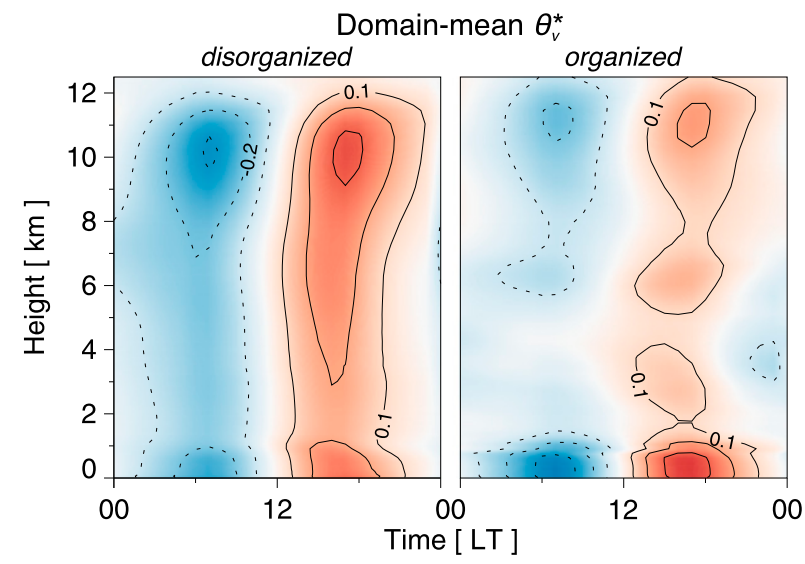

FIG. 4. Domain-mean $\theta_{v}^{*}$ (diurnal anomaly; shaded and contoured every $0.1 \mathrm{~K}$ ) for the (left) disorganized and (right) organized composite periods in CTL. 


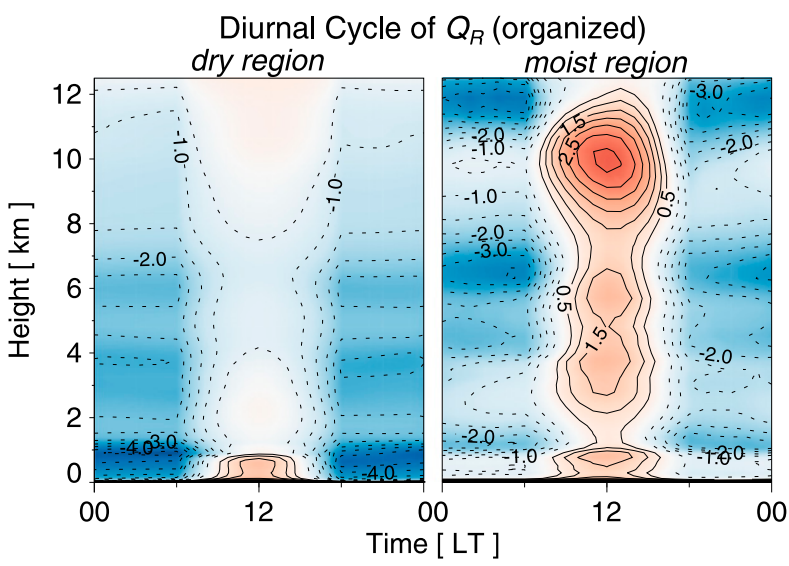

FIG. 5. The diurnal cycle of $Q_{R}$ (shaded and contoured every $0.5 \mathrm{~K} \mathrm{day}^{-1}$ ) averaged over (left) D and (right) $\mathrm{M}$ (cf. Fig. 2) in the organized period in CTL.

is therefore largely due to the much greater area of $\mathrm{D}$, which dominates the domain average (Fig. 4).

Despite the differences in the diurnal variation of $\theta_{v}^{*}$ between the two periods, this evolution is qualitatively consistent with the lapse-rate mechanism: specifically, the morning is characterized by cold anomalies that increase in magnitude with height through the troposphere, whereas warm anomalies increase with height in the afternoon because of top-heavy shortwave CRF (Kraus 1963; Randall et al. 1991; Xu and Randall 1995). These patterns tend to promote convection in the morning hours and suppress it in the afternoonpremidnight hours (Fig. 3a). The lapse-rate mechanism is likely not the entire story, however, as diurnal changes in differential radiation may also play an important role in modulating convection.

The diurnal cycle of differential $Q_{R}$ between the moist and dry regions is shown in Fig. 6. The pattern of differential $Q_{R}$ in the disorganized period is very weak, owing to very little circulation and spatial humidity variation (Figs. 2a and 6a). Nevertheless, the signature of daytime upper-level warming as a result of shortwave $\mathrm{CRF}$ in more moist (i.e., cloudy) regions is evident. The much more pronounced differential- $Q_{R}$ pattern in the organized period exemplifies the diurnally varying $\mathrm{CRF}$ resulting from deep convection and the abundance of optically thick clouds throughout the column of the convective region (Fig. 6b). The clear-air effects of organized water vapor, such as locally reduced longwave cooling in the convective region where humidity is greatest, are also included in this differential- $Q_{R}$ pattern; such effects cannot be distinguished from CRF through this perspective. This differential- $Q_{R}$ pattern is characterized by top-heavy differential warming in daytime (0600-1800 LT) owing to shortwave CRF, such

Differential $Q_{R}$

(a) CTL (disorganized)

(b) CTL (organized)

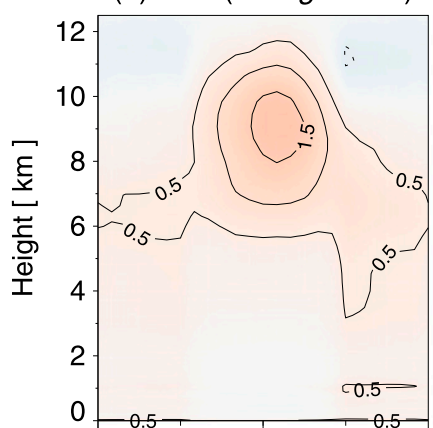

(c) H-RAD

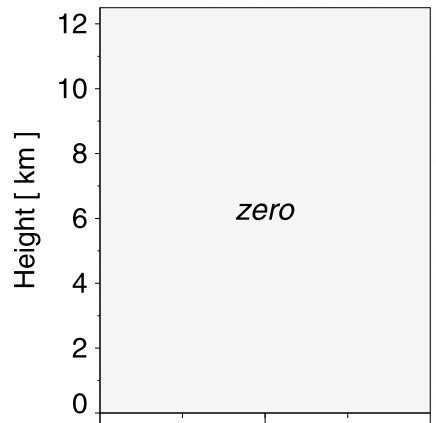

(e) HRAD-MPATCH

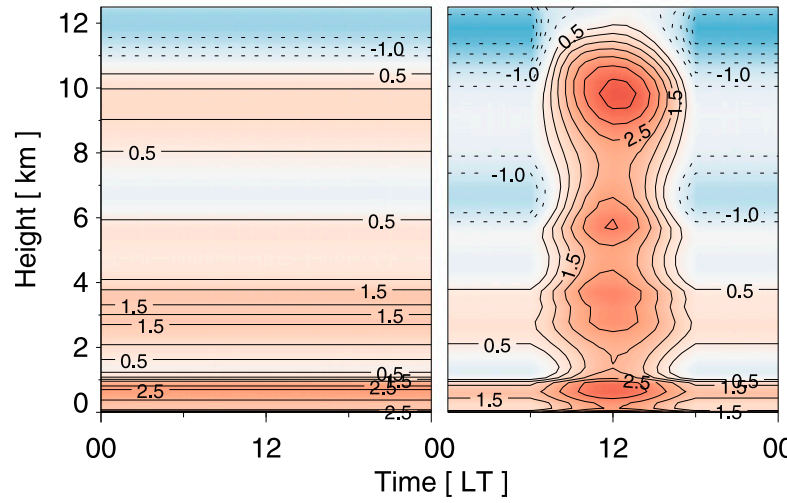

FIG. 6. Differential $Q_{R}$ (shaded and contoured every $0.5 \mathrm{~K}$ day $^{-1}$ ) for (a),(b) both composite periods in CTL and (c)-(f) for the sensitivity simulations, calculated as $\left.Q_{R}\right|_{\mathrm{M}}-\left.Q_{R}\right|_{\mathrm{D}}$, where the subscripts $\mathrm{M}$ and $\mathrm{D}$ denote averaging over the moist and dry patches, respectively. The sensitivity simulations H-RAD, P-RAD, HRADMPATCH, and DC-MPATCH are described in section 4c.

that the warming increases with height from the PBL to the midtroposphere, with peak warming at around $10 \mathrm{~km}$. At night, in contrast, differential warming is bottom heavy because of longwave CRF and longwavewater vapor interaction, with peaks in warming in the PBL and from 2 to $4 \mathrm{~km}$, and reduced warming at higher levels. Nocturnal peaks in differential cooling are evident between 6 and $8 \mathrm{~km}$ and from 10 to $12 \mathrm{~km}$, both of which are caused by $Q_{R}$ in the moist region (Fig. 5). These cooling peaks are likely situated at the top 


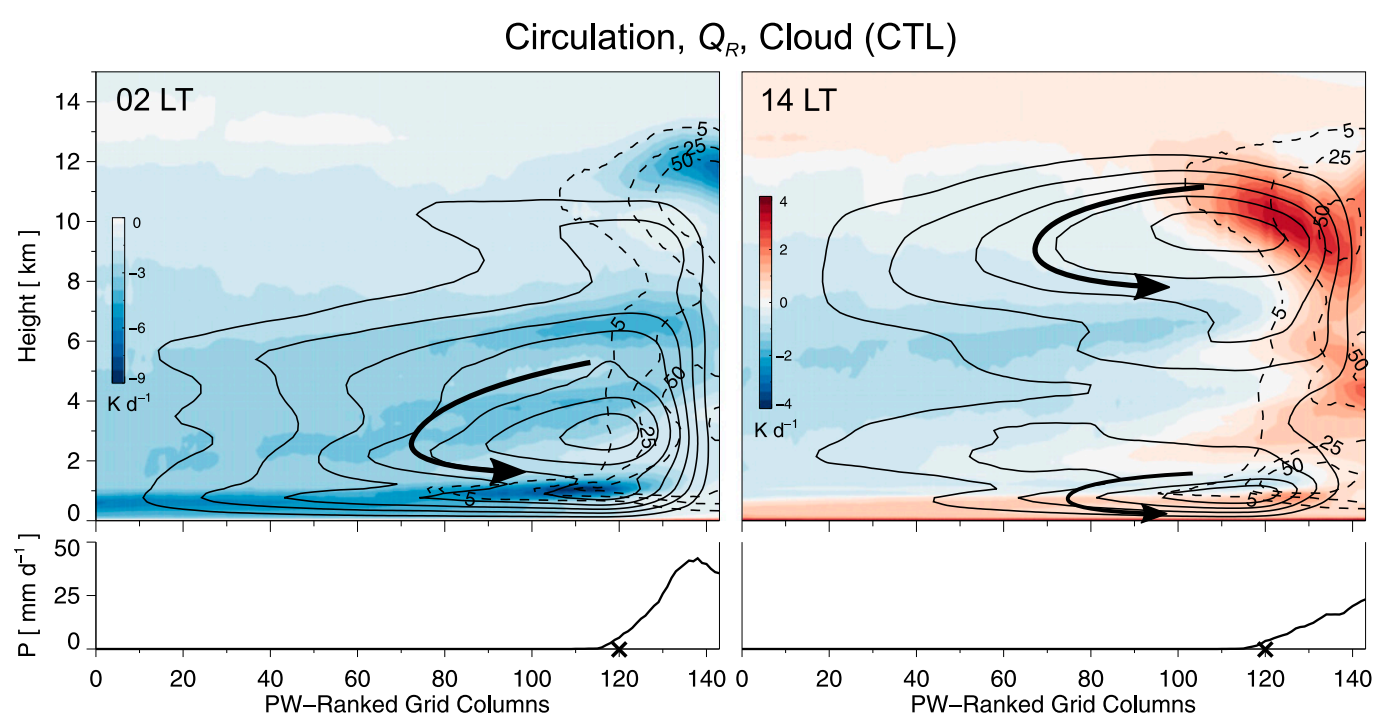

FIG. 7. PW-sorted vertical cross sections at (left) 0200 and (right) 1400 LT in the 50-59-day composite of CTL, with total $Q_{R}$ (shaded), streamfunction (solid) calculated from PW-sorted $w$ (contoured every $0.1 \mathrm{~kg} \mathrm{~m}^{-2} \mathrm{~s}^{-1}$, with only negative values appearing), cloud liquid plus ice water content (dashed; $\mathrm{mg} \mathrm{kg}^{-1}$ ), and precipitation at the bottom of the panels. The crosses indicate the dividing point between $\mathrm{M}$ and $\mathrm{D}$.

of cloud layers and/or humid layers (Webster and Stephens 1980).

An important misconception in the hypothesized mechanism of Gray and Jacobson (1977) must be addressed here. Specifically, Gray and Jacobson (1977) argued that the diurnal variation of $Q_{R}$ is minimal within convective regions, and that the diurnal cycle is primarily driven by $Q_{R}$ variations in the cloud-free surroundings. Figure 5 indicates that the diurnal cycle of $Q_{R}$ is in fact larger within the convective region through much of the column as a result of shortwave CRF and water vapor effects. Nevertheless, an important, original aspect of the hypothesis of Gray and Jacobson (1977) will be further considered in this study-namely, that diurnal changes in differential $Q_{R}$ cause important changes in circulation, and hence precipitation.

Diurnal circulation changes are described next. Circulation is shown through PW-sorted vertical cross sections in the organized period at 0200 and $1400 \mathrm{LT}$, that is, the times of precipitation extrema (Fig. 7). Circulation is depicted through an effective streamfunction $\Psi$, calculated following Bretherton et al. (2005) according to $\Psi_{i}(z)=\Psi_{i-1}+\bar{\rho}(z) w_{i-1 / 2}(z)$, where $i=1,2, \ldots, 144$ refers to each grid column on the coarsened grid sorted by $\mathrm{PW}$, and beginning from $\Psi_{1}=0$.

At 0200 LT, circulation exhibits a pronounced bottom-heavy structure in association with enhanced precipitation in the convective region. Radiative cooling prevails, with enhanced cooling from deep-convective cloud tops around $12 \mathrm{~km}$, shallow cloud tops near the top of the boundary layer between columns 80 and 120, and from the moist boundary layer in the drier columns. Layers of enhanced cooling originating from the convective region around 4 and $7 \mathrm{~km}$ are also apparent, indicative of thin cloud layers or vertical humidity gradients, which slope downward because of subsidence. Cooling is substantially weaker from the surface to around $4 \mathrm{~km}$ within the convective region, because of both increased water vapor and the prevalence of deep clouds. This pattern of reduced cooling relative to the dry region is consistent with the nocturnal low-level warming structure in differential $Q_{R}$ (Fig. 6b). This cross section provides cursory evidence for the nocturnal invigoration of convection through both cloud-top radiative cooling and differential $Q_{R}$. In this sense, the diurnal mechanisms related to lapse-rate changes and differential $Q_{R}$ are difficult to isolate in organized convection.

The circulation at $1400 \mathrm{LT}$ is much weaker at low levels, yet with enhanced circulation in the upper troposphere coinciding with top-heavy shortwave warming in the convective region (Figs. 5 and 6b). A very shallow circulation linked to boundary layer clouds and radiative cooling is also apparent (Muller and Held 2012; Naumann et al. 2017). The diurnal minimum in precipitation implies much weaker convection at this time, as corroborated by reduced deep circulation and reduced cloud water content through much of the column compared to $0200 \mathrm{LT}$.

These diurnal changes in circulation are qualitatively consistent with those of the local Hadley cell linked to the ITCZ in the Indian Ocean described by Ciesielski et al. (2018). Specifically, Ciesielski et al. (2018) noted a 
WTG Balance Assessment

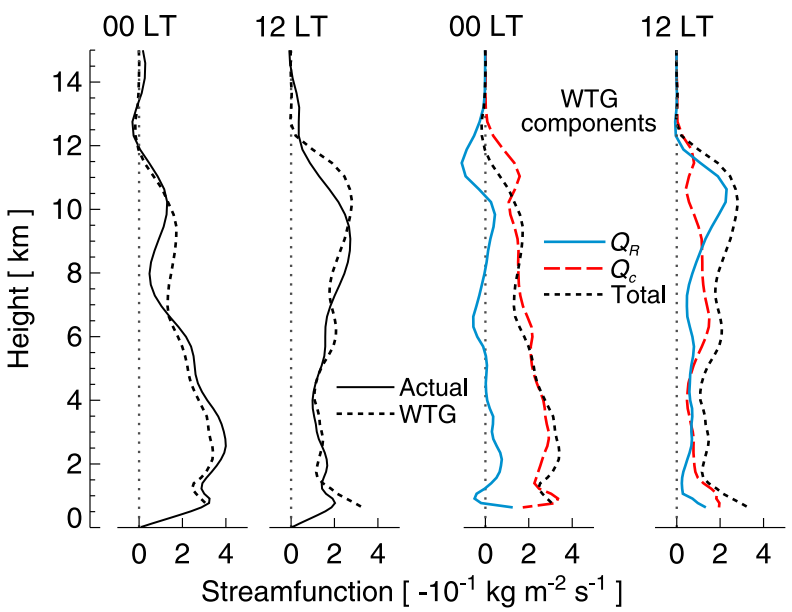

FIG. 8. Domain-averaged streamfunction in the organized composites of CTL, calculated from $w$ ("actual"), compared with that from the WTG-balanced motion for $Q_{R}, Q_{c}$, and $Q_{1}$ (Total).

transition within the ITCZ region from bottom-heavy upward motion overnight, when deep convection is strongest, to top-heavy upward motion by midday. These diurnal changes were found to be associated with analogous changes in the subsidence roughly $10^{\circ}$ of latitude to the north, indicating that these diurnal signatures in the ITCZ are linked to large-scale diurnal changes in the Hadley circulation.

The WTG approximation is now exploited to attribute these diurnal circulation changes to the diabatic forcing terms. Specifically, Eq. (3) is first rearranged to diagnose vertical motion from strict WTG balance, $w_{\mathrm{wtg}}=Q_{1} /(\partial \bar{s} / \partial z)^{-1}$, calculated at heights of $1.5 \mathrm{~km}$ and above. This calculation is performed with both $Q_{R}$ and $Q_{c}$ in place of $Q_{1}$. The domain-averaged values of $Q_{R}$ and $Q_{c}$ do not affect overturning circulation, as Eq. (4) is strictly obeyed in the domain average. These averages are therefore subtracted prior to the calculation. The value of $\Psi$ is then calculated for each term in the same manner as described earlier. This calculation therefore characterizes the circulation forcing by differential heating from each source.

Overall, WTG balance is a good approximation for the circulation at both 0000 and $1200 \mathrm{LT}$, as the gross features of the "actual" streamfunction profiles are well replicated by the WTG-deduced streamfunction (Fig. 8). The nighttime bottom-heavy circulation signature shown in cross sections (Fig. 7) is apparent in both profiles, along with the daytime top-heavy signature coinciding with weaker low-level circulation. The streamfunction profiles deduced from the individual heat sources indicate that, in the case of the nocturnal bottom-heavy profile, $Q_{c}$ dominates in terms of the (a) $Q_{c}(\mathrm{CTL})$

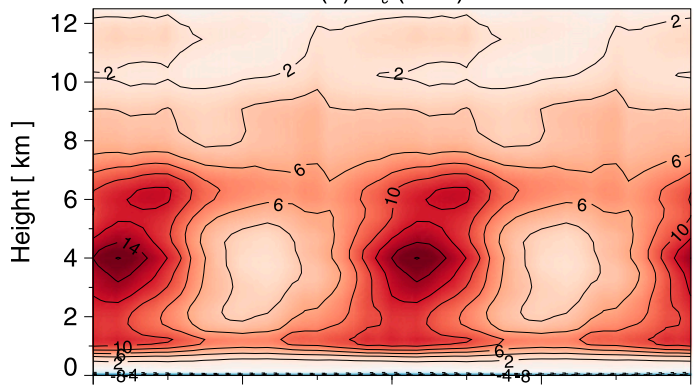

(b) $\theta_{v}{ }^{\prime}$ and Circulation (CTL)

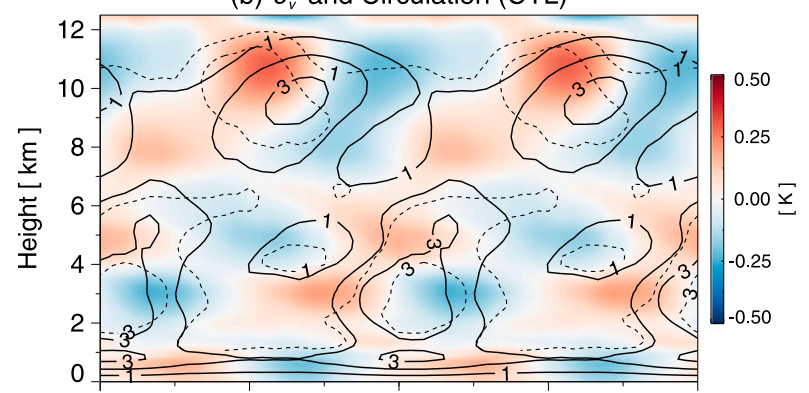

(c) $\theta_{v}{ }^{\prime}$ and Circulation (HRAD-MPATCH)

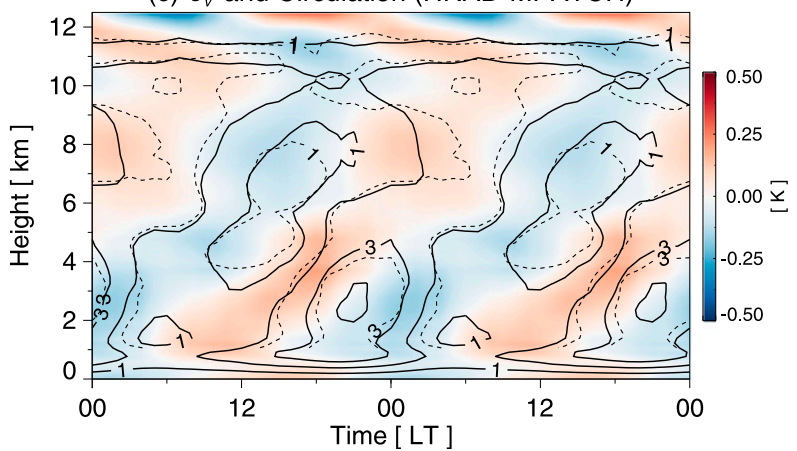

FIG. 9. (a) Diurnal time-height series of $Q_{c}$ (shaded and contoured every $2 \mathrm{~K} \mathrm{day}^{-1}$ ) averaged over $\mathrm{M}$ for the organized period in CTL, repeated for detail; (b) $\theta_{v}^{\prime}$ (horizontal anomaly; shaded; K) averaged over $\mathrm{M}$ and domain-averaged actual (solid) and WTGbalanced (dashed) streamfunction $\left(10^{-1} \mathrm{~kg} \mathrm{~m}^{-2} \mathrm{~s}^{-1}\right)$; and (c) As in (b), but for the simulation HRAD-MPATCH.

magnitude of circulation forcing. The diurnal composite of $Q_{c}$ is shown in Fig. 9a. Here, $Q_{c}$, or more accurately the differential heating resulting from $Q_{c}$, is much greater in magnitude than differential $Q_{R}$ (Fig. 6b). During daytime, the magnitudes of these circulation profiles are similar. In fact, circulation forcing by differential $Q_{R}$ in association with the top-heavy shortwave heating is evidently critical to the upper-tropospheric circulation signature at 1200 LT. This radiatively driven circulation may be important for sustaining thick high clouds in conjunction with the local destabilizing effects of radiation (Webster and Stephens 1980).

There are two plausible interpretations concerning the bottom-heavy nocturnal circulation (Fig. 8). On one hand, the dominance of $Q_{c}$ over $Q_{R}$ in the magnitude of 
TABLE 2. Description of sensitivity simulations, including the motivating science question (second column) and the method for conducting them (third column).

\begin{tabular}{lcc}
\hline \hline \multicolumn{1}{c}{ Simulation } & \multicolumn{1}{c}{ Question } & Method \\
\hline H-RAD (10 days) & $\begin{array}{c}\text { Is the differential radiation mechanism important } \\
\text { in a regime of scattered convection? }\end{array}$ & $\begin{array}{c}\text { Radiation is homogenized at each time step. } \\
\text { Simulation is initialized from homogeneous } \\
\text { base state. }\end{array}$ \\
$\begin{array}{ll}\text { P-RAD (20 days) } \\
\text { Can the diurnal cycle of organized convection be } \\
\text { reproduced using imposed radiative forcing } \\
\text { based on CTL, with the pattern of organized } \\
\text { convection retained? }\end{array}$ & $\begin{array}{c}\text { A repeating diurnal cycle of shortwave forcing is } \\
\text { imposed in a restart from day 50 of CTL, } \\
\text { using the 50-59-day composite and with longwave } \\
\text { fixed to daily mean. }\end{array}$ \\
$\begin{array}{l}\text { Is the diurnal variation of radiation in the dry } \\
\text { region surrounding convection important to } \\
\text { (20 days) }\end{array}$ & $\begin{array}{c}\text { As in P-RAD, but with shortwave radiation fixed } \\
\text { to daily mean outside of the moist patch. }\end{array}$ \\
$\begin{array}{l}\text { the diurnal cycle? } \\
\text { HRAD-MPATCH }\end{array}$ & $\begin{array}{c}\text { Is the diurnal variation of differential radiation } \\
\text { critical to the diurnal cycle? }\end{array}$ & $\begin{array}{c}\text { As in P-RAD, but with diurnal cycle of } \\
\text { shortwave heating homogeneously imposed } \\
\text { using that averaged over the moist patch. }\end{array}$ \\
\hline
\end{tabular}

circulation forcing may be taken to indicate that lapserate forcing is critical for the direct invigoration of convection. On the other hand, differential- $Q_{R}$ forcing may hypothetically strengthen low-level circulation initially, and convection in consequence, which then strongly amplifies circulation through $Q_{c}$. There is indeed a low-level peak in WTG-deduced circulation from $Q_{R}$ from 1 to approximately $4 \mathrm{~km}$, which relates to the nocturnal differential- $Q_{R}$ warming pattern resulting from reduced (enhanced) longwave cooling in the moist (dry) region (Figs. 6b and 7).

To better demonstrate the relationships between diurnal circulation adjustments and $Q_{c}$, the diurnal evolution of domain-averaged streamfunction, including the WTG-deduced counterpart, is depicted with $\theta_{v}^{\prime}$ averaged over the moist region in Fig. 9b. The notation with a prime indicates an anomaly with respect to the domain average; $\theta_{v}^{\prime}$ therefore indicates localized buoyancy anomalies, and the gravity waves that in turn drive circulation adjustment. This depiction clearly demonstrates the diurnal switch between bottom-heavy and top-heavy circulation. Comparison between Figs. 9a and $9 \mathrm{~b}$ reinforces the notion that the magnitude of nocturnal $Q_{c}$-heating is important for the strength of the bottomheavy circulation; however, warm anomalies in $\theta_{v}^{\prime}$ always appear preceding the peaks in streamfunction by several hours, demonstrating the subtle yet potentially important influence of gravity waves in adjusting circulation. For example, a warm anomaly from 2 to approximately $4 \mathrm{~km}$ increases through the afternoon. This localized warming is consistent with the aforementioned low-level differential radiative cooling pattern, and may therefore imply the importance of differential $Q_{R}$ for the evening increase in low-level circulation and convective invigoration. Additionally, a larger-magnitude $\theta_{v}^{\prime}$ anomaly appears centered at around $11 \mathrm{~km}$ shortly after
1200 LT, preceding the increase in upper-level circulation. This anomaly is evidence of circulation adjustment driven by daytime top-heavy shortwave heating (Fig. 8). Sensitivity tests presented in the next section will allow for the testing of these claims.

The replication of diurnal circulation changes by the WTG-deduced counterpart in Fig. 9b is remarkable, which further corroborates the notion that WTG balance is maintained to first order through the diurnal cycle.

\section{c. Diurnal cycle mechanisms}

Several sensitivity simulations are conducted in order to better isolate the relative impacts of the diurnal cycle mechanisms in both disorganized and organized convection. These simulations and their motivation are summarized in Table 2. To isolate the role of the two diurnal mechanisms in disorganized convection, a 10-day simulation is conducted called homogenized radiation (H-RAD). H-RAD is initialized in an identical manner to CTL, but with radiation homogenized at each time step. Homogenizing radiation disables selfaggregation (Bretherton et al. 2005; Wing and Emanuel 2014; Muller and Bony 2015; Wing et al. 2017), and disables the dynamic differential radiation mechanism. Differential $Q_{R}$ is indeed zero in H-RAD (Fig. 6c), as compared to the weak pattern in CTL (Fig. 6a). Comparison between H-RAD and the disorganized state of CTL will therefore indicate the importance of this diurnal mechanism in disorganized conditions.

Both the mean and diurnal amplitude of domainaveraged precipitation in H-RAD are virtually identical to that in the disorganized composite of CTL (Fig. 3b; Table 1). The daytime-evening evolution of precipitation in H-RAD is shifted $2 \mathrm{~h}$ earlier than that in CTL, however. This comparison therefore implies that 
the amplitude of the diurnal cycle in disorganized conditions is governed by the lapse-rate mechanism to first order.

An additional set of sensitivity simulations is conducted to investigate aspects of the diurnal mechanisms in organized convection. In these simulations, we need to keep the daily mean differential radiative forcing that sustains the organization unmodified. To do so, radiative forcing is prescribed using a periodic diurnal composite that includes this differential pattern, that is, $Q_{p}=$ $Q_{p}(x, y, z, t)$, where $Q_{p}$ is prescribed longwave plus shortwave heating. The variable $Q_{p}$ is calculated by taking the diurnal composite of $Q_{R}$ from 50 to 59 days of CTL. Moreover, we expect that the diurnal cycle of longwave cooling is not important to the diurnal cycle. The longwave tendency is therefore set to its daily mean at each model grid point to simplify interpretations. We call this simulation prescribed radiation (P-RAD), and use it as a proof of concept to demonstrate that the above changes do not impact the diurnal cycle to first order. The model is restarted from the 50-day state of CTL, and is integrated for 20 days with the forcing $Q_{p}$. The first 10 days undergo changes resulting from spurious effects and are therefore discarded.

The differential- $Q_{R}$ pattern in P-RAD, shown in Fig. 6d, closely resembles that in the organized period of CTL (Fig. 6b). Differences solely relate to the neglect of diurnal variations in longwave heating. Domainaveraged precipitation from 10 to 19 days in P-RAD is $3.28 \mathrm{~mm} \mathrm{day}^{-1}$, comparing well with $3.20 \mathrm{~mm} \mathrm{day}^{-1}$ in the organized period of CTL (Table 1). The diurnal amplitude is $1.73 \mathrm{~mm} \mathrm{day}^{-1}$ in P-RAD, compared with $1.22 \mathrm{~mm} \mathrm{day}^{-1}$ in CTL. The amplified diurnal cycle in $\mathrm{P}-\mathrm{RAD}$ is due to a larger, sharper nocturnal peak compared to CTL, which is also shifted $2 \mathrm{~h}$ later than CTL, peaking at $0400 \mathrm{LT}$ (Fig. 3c). These differences may owe to the neglect of cloud-radiation interaction, or from neglect of the diurnal cycle of longwave heating. Despite these differences, P-RAD successfully replicates the gross features of the diurnal cycle in CTL.

Described next are two sensitivity experiments, which are conducted identically to P-RAD, though with modified diurnal cycle characteristics. The daily mean shortwave heating at all model grid points is unchanged in both experiments.

The first sensitivity experiment, diurnal cycle in moist patch (DC-MPATCH), is conducted to test the specific hypothesis of Gray and Jacobson (1977) - that the diurnal cycle of radiative heating outside of the convective region drives the diurnal cycle of the deep convection. Specifically, this effect is disabled in DC-MPATCH by fixing shortwave heating to its daily mean at all points in the dry region, while retaining the diurnal cycle within the convective region (M). Comparison of the differential- $Q_{R}$ pattern between CTL and DC-MPATCH demonstrates the impact of this change (Figs. $6 \mathrm{~b}, \mathrm{f}$ ): the diurnal variation of differential heating is substantially reduced in the layer extending from the boundary layer to $4 \mathrm{~km}$. Most importantly, differential warming within this layer is greatest at noon in DC-MPATCH. Therefore, if the differential radiation mechanism is of firstorder importance for the diurnal cycle, precipitation should instead peak during the day when differential warming is greatest.

The diurnal cycle of precipitation in DC-MPATCH is reduced by $34 \%$ relative to $\mathrm{P}-\mathrm{RAD}$, from 1.73 to $1.14 \mathrm{~mm}$ day $^{-1}$ (Table 1 ), although the phasing remains very similar to that in P-RAD (Fig. 3d). The amplitude reduction is caused by both a reduced peak and a quasiflattened minimum. The small relative maximum at $1700 \mathrm{LT}$ likely owes to increased daytime differential warming in the surface-4-km layer, as noted above (Fig. 6b). These results indicate that diurnal changes in radiation in the dry region are, at most, of second-order importance to the diurnal cycle.

The second sensitivity experiment, homogenized radiation based on moist patch (HRAD-MPATCH), is conducted to quantify the total impact of the differential- $Q_{R}$ mechanism. While DC-MPATCH isolates this mechanism in relation to diurnal $Q_{R}$ forcing specifically in the dry region, diurnal changes in differential $Q_{R}$ are disabled entirely in HRAD-MPATCH. This is achieved by imposing a horizontally homogeneous diurnal cycle of radiative heating, which is set to be the diurnal cycle averaged over the convective region of CTL, that is, that shown in Fig. 5, right. The pattern of differential $Q_{R}$ in HRAD-MPATCH therefore has no diurnal cycle (Fig. 6e). Rather, it depicts the daily mean differential$Q_{R}$ forcing that sustains the organization.

The diurnal amplitude of precipitation in HRADMPATCH is also reduced relative to P-RAD, by $27 \%$ from 1.73 to $1.26 \mathrm{~mm} \mathrm{day}^{-1}$ (Fig. 3d). More noteworthy is a remarkable phase shift, with the peak in HRADMPATCH preceding that in P-RAD by $5 \mathrm{~h}$. This shift is also apparent in the streamfunction, which is characterized by peak circulation in the lower troposphere from 1800 to 0000 LT (Fig. 9c). A consistent, albeit less dramatic, phase shift can also be noted in H-RAD, in comparison to the disorganized period of CTL (Fig. 3b).

This phase shift can be understood as follows. In both CTL and DC-MPATCH, the top-heavy temperature changes resulting from diurnal changes in CRF within the convective region are damped by gravity waves, which spread localized buoyancy anomalies from the convective region into the dry region. Since the diurnal cycle of $Q_{R}$ is horizontally homogenized in HRAD-MPATCH, 


\section{Diurnal Cycle in Organized Convection}

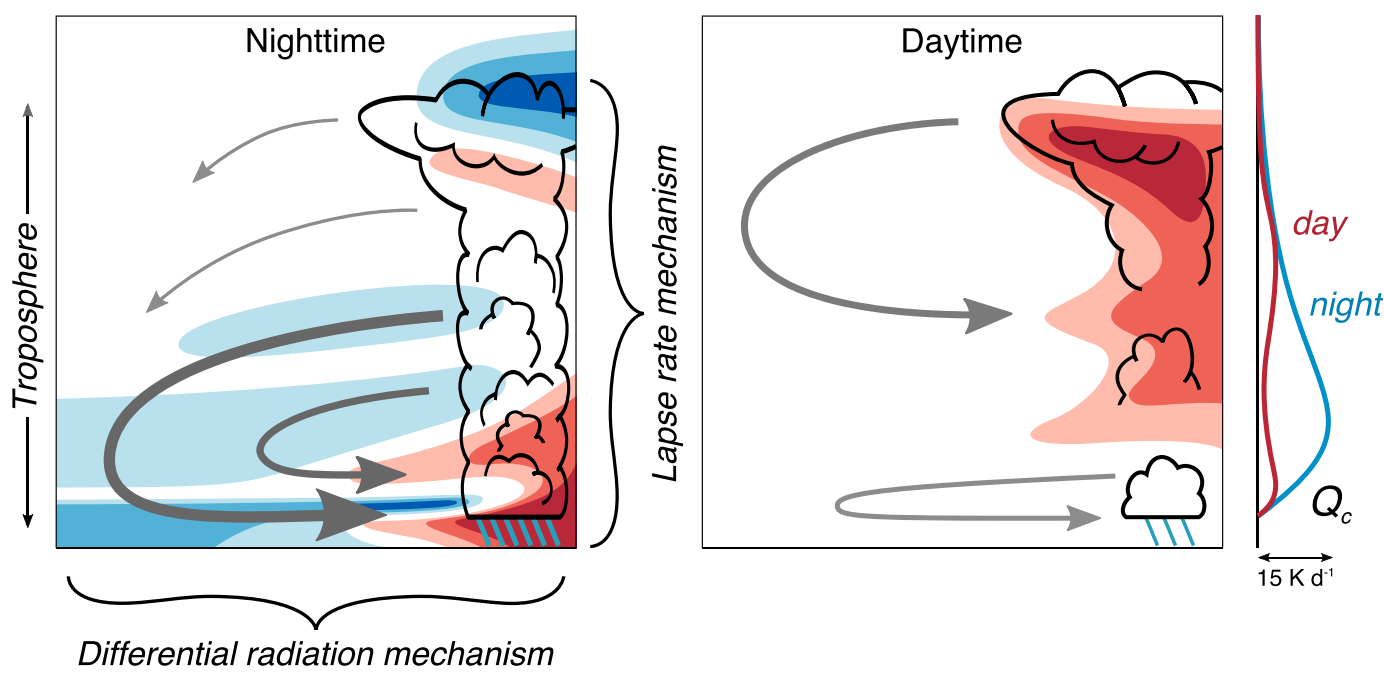

FIG. 10. Schematic depiction of the diurnal cycle of organized deep convection, with differential radiative heating $Q_{R}$ (shading), convective heating $Q_{c}$ (profiles), and the characteristic features in convective clouds, circulation, and rainfall.

however, its direct impact on temperature is also horizontally homogeneous. Gravity waves and changes in circulation are therefore not directly driven by $Q_{R}$ in HRAD-MPATCH [cf. Eq. (4)]. In consequence, the diurnal changes in temperature and lapse rate are greater in magnitude as compared to those in CTL and DCMPATCH (not shown). Convection responds earlier in the day to these amplified diurnal lapse-rate changes. Furthermore, in CTL the diurnal cycle of differential $Q_{R}$ between the surface and about $4 \mathrm{~km}$ favors a diurnal cycle in circulation that invigorates convection beginning in the late evening, around 1800-2100 LT (Fig. 9b). Since diurnal changes in differential $Q_{R}$ are disabled in HRAD-MPATCH, circulation instead increases quite immediately in the afternoon as shortwave heating decreases and convection intensifies (Fig. 9c).

This finding indicates that the diurnal circulation adjustment process driven by gravity waves and caused fundamentally by differential $Q_{R}$ is critical to the timing of the diurnal cycle, whereas its impacts on the diurnal range of precipitation are secondary (driven primarily by the lapse-rate mechanism). The differential radiation mechanism therefore explains the tendency for organized deep convection to peak in the early morning, instead of the middle-overnight period, over much of the tropical and subtropical oceans (Mapes and Houze 1993; Nesbitt and Zipser 2003; Kikuchi and Wang 2008).

Additionally, the signature of top-heavy circulation apparent in CTL is absent from HRAD-MPATCH (Fig. 9c). This confirms the importance of gravity waves and circulation adjustment in association with localized top-heavy shortwave heating over the convective region for this feature.

\section{Conclusions}

This study has investigated the diurnal cycle of tropical organized deep convection and the response in large-scale circulation. Considerations of weak temperature gradient (WTG) theory aid the interpretation of diurnal convection-circulation interaction. Given the finite phase speed of gravity waves, we find that the time scale of circulation adjustment into WTG balance increases with increasing horizontal scale, though with a short time scale of $<6 \mathrm{~h}$ for spatial scales typical of organized convection $(\leq 500 \mathrm{~km})$. This short time scale implies that diurnal changes in the localized diabatic heating associated with organized convective systems drive pronounced changes in the large-scale circulation they are coupled to. This finding is supported by comparing the diurnal cycle of circulation in a numerical simulation that deduced through WTG balance, which match remarkably well.

This study has examined the specific hypothesis that diurnal changes in both lapse rate and cloudy-clear differential radiative heating are vital to the diurnal cycle of organized tropical deep convection. Support for this hypothesis has been provided through convectionpermitting model simulations of self-aggregation in diurnal RCE. The principal findings from these simulations are depicted schematically in Fig. 10. At night, longwave cooling from cloud top in the absence of 
shortwave warming invigorates convection (the lapserate mechanism), which in turn strengthens bottomheavy circulation through convective heating $Q_{c}$. As a secondary effect, the differential longwave cooling between the dry and moist regions when shortwave warming is absent bolsters this circulation, and hence the convection (the differential radiation mechanism). Shortwave warming during daytime reduces the differential radiative warming of the convective region at low levels, but enhances it at upper levels because of the topheavy shortwave absorption in areas of deep convection. Although this top-heavy warming suppresses deep convection, it strengthens circulation at upper levels.

Sensitivity experiments further indicate that the diurnal range of precipitation in organized convection is governed to first order by the lapse-rate mechanism, while the differential radiation mechanism amplifies this range by approximately $30 \%$. The differential radiation mechanism delays the nocturnal peak by around $5 \mathrm{~h}$, however, and is therefore important for the tendency for heavy precipitation in tropical organized convection to peak in the early morning. Sensitivity experiments additionally indicate that the top-heavy pattern of shortwave warming in deep convection is critical to the development of an enhanced upper-level circulation during daytime hours (Fig. 10).

In the context of the growing body of work on RCE simulations of self-aggregation (Wing et al. 2017), this study is the first of such studies to describe the diurnal cycle in convection and circulation. This study has demonstrated that the differential radiation pattern resulting from longwave-cloud and longwave-water vapor interactions, which is critical to self-aggregation on multiday time scales, is virtually reversed during daytime by shortwave heating. This reversal, in turn, drives pronounced changes in circulation (Fig. 10). An important future step is investigating the consequences of this pronounced diurnal cycle on the multiday evolution and equilibrium state of self-aggregation.

Diurnal changes in the character of large-scale circulation simulated herein through the idealized RCE approach are qualitatively similar to diurnal changes in the Hadley cell driven by the ITCZ. Specifically, Ciesielski et al. (2018) found that the nighttime invigoration of convection in the ITCZ leads to enhanced bottom-heavy upward motion in that region, with enhanced deep subsidence displaced by approximately $10^{\circ}$ of latitude, that is, in the descending branch of the Hadley cell. During daytime, upward motion in the ITCZ evolves to a distinctly top-heavy profile, with similarly top-heavy subsidence in the descending branch. This daytime enhancement of top-heavy circulation may explain some observations that have to date puzzled investigators.
Namely, Bain et al. (2010) found that the eastern Pacific ITCZ is characterized by two peaks in high clouds-one in the early morning, and another in the midafternoon, while Gupta et al. (2018) extended this finding to multiyear satellite observations across the tropics using CloudSat radar. A similar afternoon peak in the outflow cirrus of tropical cyclones has been found, despite the primary early-morning peak in precipitation (Dunion et al. 2014; Leppert and Cecil 2016). The results of this study suggest that the circulation at upper levels is driven distinctly from deep convection, specifically by the localized top-heavy shortwave warming in convective regions. At night, in contrast, longwave-cloud interaction may support a more bottom-heavy mass flux profile, and hence enhanced low-level convergence and cyclone spinup (Davis and Ahijevych 2012; Nicholls 2015). The circulation and gravity wave dynamics in the rotating environment of tropical cyclones are distinct from those described here, however (O'Neill et al. 2017). This notion must therefore be examined in a separate study.

Acknowledgments. J. H. R gratefully acknowledges funding from the National Science Foundation (Grant AGS-1524844) and Alexander von Humboldt Foundation/ Stiftung. We are indebted to Paul Ciesielski, Richard Johnson, Chris Bretherton, Robert Pincus, Tobias Becker, and Bjorn Stevens for insightful discussions on this work. We additionally thank Guido Cioni, Monika Esch, and Uwe Schulzweida for technical assistance. The comments from Ann Kristin Naumann and two anonymous reviewers led to substantial improvements in the clarity of this study. We acknowledge the supercomputing resources provided by the Deutsches Klimarechenzentrum (DKRZ) highperformance computing center. Primary model code and postprocessing scripts used in this study are archived by the Max Planck Institute for Meteorology, and may be obtained by contacting publications@mpimet.mpg.de.

\section{REFERENCES}

Bain, C. L., G. Magnusdottir, P. Smyth, and H. Stern, 2010: Diurnal cycle of the intertropical convergence zone in the east Pacific. J. Geophys. Res., 115, D23116, https://doi.org/10.1029/ 2010JD014835.

Bellenger, H., Y. N. Takayabu, T. Ushiyama, and K. Yoneyama, 2010: Role of diurnal warm layers in the diurnal cycle of convection over the tropical Indian Ocean during MISMO. Mon. Wea. Rev., 138, 2426-2433, https://doi.org/10.1175/2010MWR3249.1.

Bernie, D. J., S. J. Woolnough, J. M. Slingo, and E. Guilyardi, 2005: Modeling diurnal and intraseasonal variability of the ocean mixed layer. J. Climate, 18, 1190-1202, https://doi.org/10.1175/ JCLI3319.1.

Bowman, K. P., and M. D. Fowler, 2015: The diurnal cycle of precipitation in tropical cyclones. J. Climate, 28, 5325-5334, https://doi.org/10.1175/JCLI-D-14-00804.1. 
Bretherton, C. S., and P. K. Smolarkiewicz, 1989: Gravity waves, compensating subsidence and detrainment around cumulus clouds. J. Atmos. Sci., 46, 740-759, https://doi.org/10.1175/ 1520-0469(1989)046<0740:GWCSAD>2.0.CO;2.

- , P. N. Blossey, and M. Khairoutdinov, 2005: An energybalance analysis of deep convective self-aggregation above uniform SST. J. Atmos. Sci., 62, 4273-4292, https://doi.org/ 10.1175/JAS3614.1.

Charney, J. G., 1963: A note on large-scale motions in the tropics. J. Atmos. Sci., 20, 607-609, https://doi.org/10.1175/1520-0469 (1963)020<0607:ANOLSM>2.0.CO;2.

Chen, S. S., and R. A. Houze Jr., 1997: Diurnal variation and lifecycle of deep convective systems over the tropical Pacific warm pool. Quart. J. Roy. Meteor. Soc., 123, 357-388, https:// doi.org/10.1002/qj.49712353806.

Chikira, M., 2014: Eastward-propagating intraseasonal oscillation represented by Chikira-Sugiyama cumulus parameterization. Part II: Understanding moisture variation under weak temperature gradient balance. J. Atmos. Sci., 71, 615-639, https:// doi.org/10.1175/JAS-D-13-038.1.

Ciesielski, P. E., R. H. Johnson, W. H. Schubert, and J. H. Ruppert Jr., 2018: Diurnal cycle of the ITCZ in DYNAMO. J. Climate, https://doi.org/10.1175/JCLI-D-17-0670.1, in press.

Clough, S. A., M. W. Shephard, E. J. Mlawer, J. S. Delamere, M. J. Iacono, K. Cady-Pereira, S. Boukabara, and P. D. Brown, 2005: Atmospheric radiative transfer modeling: A summary of the AER codes. J. Quant. Spectrosc. Radiat. Transfer, 91, 233-244, https://doi.org/10.1016/j.jqsrt.2004.05.058.

Cronin, T. W., K. A. Emanuel, and P. Molnar, 2015: Island precipitation enhancement and the diurnal cycle in radiativeconvective equilibrium. Quart. J. Roy. Meteor. Soc., 141, 1017-1034, https://doi.org/10.1002/qj.2443.

Dai, A., 2006: Precipitation characteristics in eighteen coupled climate models. J. Climate, 19, 4605-4630, https://doi.org/ 10.1175/JCLI3884.1.

— , and K. E. Trenberth, 2004: The diurnal cycle and its depiction in the Community Climate System Model. J. Climate, 17, 930-951, https://doi.org/10.1175/1520-0442(2004)017<0930: TDCAID $>2.0 . \mathrm{CO} ; 2$.

Davis, C. A., and D. A. Ahijevych, 2012: Mesoscale structural evolution of three tropical weather systems observed during PREDICT. J. Atmos. Sci., 69, 1284-1305, https://doi.org/ 10.1175/JAS-D-11-0225.1.

Deser, C., and C. A. Smith, 1998: Diurnal and semidiurnal variations of the surface wind field over the tropical Pacific Ocean. J. Climate, 11, 1730-1748, https://doi.org/10.1175/ 1520-0442(1998)011<1730:DASVOT>2.0.CO;2.

Dipankar, A., B. Stevens, R. Heinze, C. Moseley, G. Zängl, M. Giorgetta, and S. Brdar, 2015: Large eddy simulation using the general circulation model ICON. J. $A d v$. Model. Earth Syst., 7, 963-986, https://doi.org/10.1002/ 2015MS000431.

Dudhia, J., 1989: Numerical study of convection observed during the Winter Monsoon Experiment using a mesoscale two-dimensional model. J. Atmos. Sci., 46, 3077-3107, https://doi.org/10.1175/1520-0469(1989)046<3077: NSOCOD $>2.0 . C O ; 2$.

Dunion, J. P., C. D. Thorncroft, and C. S. Velden, 2014: The tropical cyclone diurnal cycle of mature hurricanes. Mon. Wea. Rev., 142, 3900-3919, https://doi.org/10.1175/MWR-D-13-00191.1.

Emanuel, K., A. A. Wing, and E. M. Vincent, 2014: Radiativeconvective instability. J. Adv. Model. Earth Syst., 6, 75-90, https://doi.org/10.1002/2013MS000270.
Gray, W. M., and R. W. Jacobson Jr., 1977: Diurnal variation of deep cumulus convection. Mon. Wea. Rev., 105, 1171-1188, https:// doi.org/10.1175/1520-0493(1977)105<1171:DVODCC>2.0.CO;2.

Gupta, A. K., K. Rajeev, S. Sijikumar, and A. K. M. Nair, 2018: Enhanced daytime occurrence of clouds in the tropical upper troposphere over land and ocean. Atmos. Res., 201, 133-143, https://doi.org/10.1016/j.atmosres.2017.10.018.

Herman, M. J., and D. J. Raymond, 2014: WTG cloud modeling with spectral decomposition of heating. J. Adv. Model. Earth Syst., 6, 1121-1140, https://doi.org/10.1002/2014MS000359.

Hohenegger, C., and B. Stevens, 2016: Coupled radiative convective equilibrium simulations with explicit and parameterized convection. J. Adv. Model. Earth Syst., 8, 1468-1482, https:// doi.org/10.1002/2016MS000666.

Holloway, C. E., A. A. Wing, S. Bony, C. Muller, H. Masunaga, T. S. L'Ecuyer, D. D. Turner, and P. Zuidema, 2017: Observing convective aggregation. Surv. Geophys., 38, 11991236, https://doi.org/10.1007/s10712-017-9419-1.

Iacono, M. J., J. S. Delamere, E. J. Mlawer, M. W. Shephard, S. A. Clough, and W. D. Collins, 2008: Radiative forcing by long-lived greenhouse gases: Calculations with the AER radiative transfer models. J. Geophys. Res., 113, D13103, https://doi.org/10.1029/2008JD009944.

Johnson, R. H., 2011: Diurnal cycle of monsoon convection. The Global Monsoon System: Research and Forecast, C.-P. Chang et al., Eds., Vol. 5, World Scientific Series on Asia-Pacific Weather and Climate, 2nd ed. World Scientific, 257-276.

_ , and P. E. Ciesielski, 2017: Multiscale variability of the atmospheric boundary layer during DYNAMO. J. Atmos. Sci., 74, 4003-4021, https://doi.org/10.1175/JAS-D-17-0182.1.

,-- , and J. A. Cotturone, 2001: Multiscale variability of the atmospheric mixed layer over the western Pacific warm pool. J. Atmos. Sci., 58, 2729-2750, https://doi.org/10.1175/ 1520-0469(2001)058<2729:MVOTAM >2.0.CO;2.

,-- , and T. M. Rickenbach, 2016: A further look at $Q_{1}$ and $Q_{2}$ from TOGA COARE. Meteor. Monogr., No. 56, Amer. Meteor. Soc., 1.1-1.12, https://doi.org/10.1175/ AMSMONOGRAPHS-D-15-0002.1.

Kikuchi, K., and B. Wang, 2008: Diurnal precipitation regimes in the global tropics. J. Climate, 21, 2680-2696, https://doi.org/ 10.1175/2007JCLI2051.1.

Klemp, J. B., J. Dudhia, and A. D. Hassiotis, 2008: An upper gravitywave absorbing layer for NWP applications. Mon. Wea. Rev., 136, 3987-4004, https://doi.org/10.1175/2008MWR2596.1.

Kossin, J. P., 2002: Daily hurricane variability inferred from GOES infrared imagery. Mon. Wea. Rev., 130, 2260-2270, https:// doi.org/10.1175/1520-0493(2002)130<2260:DHVIFG > 2.0.CO;2.

Kraus, E. B., 1963: The diurnal precipitation change over the sea. J. Atmos. Sci., 20, 551-556, https://doi.org/10.1175/1520-0469 (1963) $020<0551$ :TDPCOT $>2.0$. CO;2.

Leppert, K. D., II, and D. J. Cecil, 2016: Tropical cyclone diurnal cycle as observed by TRMM. Mon. Wea. Rev., 144, 2793-2808, https://doi.org/10.1175/MWR-D-15-0358.1.

Liu, C., and M. W. Moncrieff, 1998: A numerical study of the diurnal cycle of tropical oceanic convection. J. Atmos. Sci., 55, 2329-2344, https://doi.org/10.1175/1520-0469(1998)055<2329: ANSOTD $>2.0 . \mathrm{CO} ; 2$.

Mapes, B. E., 1993: Gregarious tropical convection. J. Atmos. Sci., 50, 2026-2037, https://doi.org/10.1175/1520-0469(1993)050<2026: GTC $>2.0 . \mathrm{CO} ; 2$.

_ , and R. A. Houze Jr., 1993: Cloud clusters and superclusters over the oceanic warm pool. Mon. Wea. Rev., 121, 1398-1416, https:// doi.org/10.1175/1520-0493(1993)121<1398:CCASOT>2.0.CO;2. 
Matthews, A. J., D. B. Baranowski, K. J. Heywood, P. J. Flatau, and S. Schmidtko, 2014: The surface diurnal warm layer in the Indian Ocean during CINDY/DYNAMO. J. Climate, 27, 9101-9122, https://doi.org/10.1175/JCLI-D-14-00222.1.

Melhauser, C., and F. Zhang, 2014: Diurnal radiation cycle impact on the pregenesis environment of Hurricane Karl (2010). J. Atmos. Sci., 71, 1241-1259, https://doi.org/10.1175/JAS-D-13-0116.1.

Mlawer, E. J., S. J. Taubman, P. D. Brown, M. J. Iacono, and S. A. Clough, 1997: Radiative transfer for inhomogeneous atmospheres: RRTM, a validated correlated-k model for the longwave. J. Geophys. Res., 102, 16 663-16 682, https:// doi.org/10.1029/97JD00237.

Muller, C., and I. M. Held, 2012: Detailed investigation of the self-aggregation of convection in cloud-resolving simulations. J. Atmos. Sci., 69, 2551-2565, https://doi.org/10.1175/ JAS-D-11-0257.1.

- , and S. Bony, 2015: What favors convective aggregation and why? Geophys. Res. Lett., 42, 5626-5634, https://doi.org/ 10.1002/2015GL064260.

Naumann, A. K., B. Stevens, C. Hohenegger, and J. P. Mellado, 2017: A conceptual model of a shallow circulation induced by prescribed low-level radiative cooling. J. Atmos. Sci., $\mathbf{7 4}$ 3129-3144, https://doi.org/10.1175/JAS-D-17-0030.1.

Neale, R., and J. Slingo, 2003: The Maritime Continent and its role in the global climate: A GCM study. J. Climate, 16, 834-848, https://doi.org/10.1175/1520-0442(2003)016<0834: TMCAIR $>2.0 . \mathrm{CO} ; 2$.

Nesbitt, S. W., and E. J. Zipser, 2003: The diurnal cycle of rainfall and convective intensity according to three years of TRMM measurements. J. Climate, 16, 1456-1475, https://doi.org/ 10.1175/1520-0442-16.10.1456.

Nicholls, M. E., 2015: An investigation of how radiation may cause accelerated rates of tropical cyclogenesis and diurnal cycles of convective activity. Atmos. Chem. Phys., 15, 9029-9029, https://doi.org/10.5194/acp-15-9003-2015.

_ , R. A. Pielke, and W. R. Cotton, 1991: Thermally forced gravity waves in an atmosphere at rest. J. Atmos. Sci., 48 , 1869-1884, https://doi.org/10.1175/1520-0469(1991)048<1869: TFGWIA $>2.0 . \mathrm{CO} ; 2$.

O'Neill, M. E., D. Perez-Betancourt, and A. A. Wing, 2017: Accessible environments for diurnal-period waves in simulated tropical cyclones. J. Atmos. Sci., 74, 2489-2502, https://doi.org/ 10.1175/JAS-D-16-0294.1.

Peatman, S. C., A. J. Matthews, and D. P. Stevens, 2014: Propagation of the Madden-Julian oscillation through the Maritime Continent and scale interaction with the diurnal cycle of precipitation. Quart. J. Roy. Meteor. Soc., 140, 814-825, https:// doi.org/10.1002/qj.2161

Popke, D., B. Stevens, and A. Voigt, 2013: Climate and climate change in a radiative-convective equilibrium version of ECHAM6. J. Adv. Model. Earth Syst., 5, 1-14, https://doi.org/ 10.1029/2012MS000191.

Pritchard, M. S., and R. C. J. Somerville, 2009: Assessing the diurnal cycle of precipitation in a multi-scale climate model. J. Adv. Model. Earth Syst., 1, 12, https://doi.org/10.3894/ JAMES.2009.1.12.

Randall, D. A., Harshvardhan, and D. A. Dazlich, 1991: Diurnal variability of the hydrologic cycle in a general circulation model. J. Atmos. Sci., 48, 40-62, https://doi.org/10.1175/ 1520-0469(1991)048<0040:DVOTHC > 2.0.CO;2.

Ruppert, J. H., Jr., 2016: Diurnal timescale feedbacks in the tropical cumulus regime. J. Adv. Model. Earth Syst., 8, 1483-1500, https://doi.org/10.1002/2016MS000713.
—, and R. H. Johnson, 2015: Diurnally modulated cumulus moistening in the preonset stage of the Madden-Julian oscillation during DYNAMO. J. Atmos. Sci., 72, 1622-1647, https:// doi.org/10.1175/JAS-D-14-0218.1.

, and - 2016: On the cumulus diurnal cycle over the tropical warm pool. J. Adv. Model. Earth Syst., 8, 669-690, https:// doi.org/10.1002/2015MS000610.

Ruprecht, E., and W. M. Gray, 1976: Analysis of satellite-observed tropical cloud clusters. I. Wind and dynamic fields. Tellus, 28A, 391-413, https://doi.org/10.3402/tellusa.v28i5.11309.

Seifert, A., and K. D. Beheng, 2006: A two-moment cloud microphysics parameterization for mixed-phase clouds. Part 1: Model description. Meteor. Atmos. Phys., 92, 45-66, https:// doi.org/10.1007/s00703-005-0112-4.

Sobel, A. H., and C. S. Bretherton, 2000: Modeling tropical precipitation in a single column. J. Climate, 13, 4378-4392, https:// doi.org/10.1175/1520-0442(2000)013<4378:MTPIAS >2.0.CO;2.

- J. Nilsson, and L. M. Polvani, 2001: The weak temperature gradient approximation and balanced tropical moisture waves. J. Atmos. Sci., 58, 3650-3665, https://doi.org/10.1175/ 1520-0469(2001)058<3650:TWTGAA > 2.0.CO;2.

Sui, C.-H., K.-M. Lau, Y. N. Takayabu, and D. A. Short, 1997: Diurnal variations in tropical oceanic cumulus convection during TOGA COARE. J. Atmos. Sci., 54, 639-655, https://doi.org/10.1175/ 1520-0469(1997)054<0639:DVITOC >2.0.CO;2.

Tao, W.-K., S. Lang, J. Simpson, C.-H. Sui, B. Ferrier, and M.-D. Chou, 1996: Mechanisms of cloud-radiation interaction in the tropics and midlatitudes. J. Atmos. Sci., 53, 2624-2651, https://doi.org/ 10.1175/1520-0469(1996)053<2624:MOCRII>2.0.CO;2.

Tompkins, A. M., and G. C. Craig, 1998: Radiative-convective equilibrium in a three-dimensional cloud-ensemble model. Quart. J. Roy. Meteor. Soc., 124, 2073-2097, https://doi.org/ 10.1002/qj.49712455013.

Webster, P. J., and G. L. Stephens, 1980: Tropical upper-tropospheric extended clouds: Inferences from winter MONEX. J. Atmos. Sci., 37, 1521-1541, https://doi.org/10.1175/1520-0469-37.7.1521.

— C. A. Clayson, and J. A. Curry, 1996: Clouds, radiation, and the diurnal cycle of sea surface temperature in the tropical western Pacific. J. Climate, 9, 1712-1730, https://doi.org/ 10.1175/1520-0442(1996)009<1712:CRATDC >2.0.CO;2.

Wing, A. A., and K. A. Emanuel, 2014: Physical mechanisms controlling self-aggregation of convection in idealized numerical modeling simulations. J. Adv. Model. Earth Syst., 6, 59-74, https://doi.org/10.1002/2013MS000269.

, and T. W. Cronin, 2016: Self-aggregation of convection in long channel geometry. Quart. J. Roy. Meteor. Soc., 142, 1-15, https://doi.org/10.1002/qj.2628.

, K. Emanuel, C. E. Holloway, and C. Muller, 2017: Convective self-aggregation in numerical simulations: A review. Surv. Geophys., 38, 1173-1197, https://doi.org/10.1007/s10712-017-9408-4.

Wolding, B. O., E. D. Maloney, and M. Branson, 2016: Vertically resolved weak temperature gradient analysis of the MaddenJulian oscillation in SP-CESM. J. Adv. Model. Earth Syst., 8, 1586-1619, https://doi.org/10.1002/2016MS000724.

Wood, R., C. S. Bretherton, and D. L. Hartmann, 2002: Diurnal cycle of liquid water path over the subtropical and tropical oceans. Geophys. Res. Lett., 29, 2092, https://doi.org/10.1029/2002GL015371.

Woolnough, S. J., J. M. Slingo, and B. J. Hoskins, 2004: The diurnal cycle of convection and atmospheric tides in an aquaplanet GCM. J. Atmos. Sci., 61, 2559-2573, https://doi.org/10.1175/JAS3290.1.

Xu, K.-M., and D. A. Randall, 1995: Impact of interactive radiative transfer on the macroscopic behavior of cumulus ensembles. Part II: Mechanisms for cloud-radiation interactions. J. Atmos. Sci., 
52, 800-817, https://doi.org/10.1175/1520-0469(1995)052<0800: IOIRTO $>2.0 . \mathrm{CO} ; 2$.

Yanai, M., S. Esbensen, and J.-H. Chu, 1973: Determination of bulk properties of tropical cloud clusters from large-scale heat and moisture budgets. J. Atmos. Sci., 30, 611-627, https:// doi.org/10.1175/1520-0469(1973)030<0611:DOBPOT>2.0.CO;2.

Yang, G.-Y., and J. Slingo, 2001: The diurnal cycle in the tropics. Mon. Wea. Rev., 129, 784-801, https://doi.org/ 10.1175/1520-0493(2001)129<0784:TDCITT > 2.0.CO;2.

Yang, S., and E. A. Smith, 2006: Mechanisms for diurnal variability of global tropical rainfall observed from TRMM. J. Climate, 19, 5190-5226, https://doi.org/10.1175/JCLI3883.1.
_ K.-S. Kuo, and E. A. Smith, 2008: Persistent nature of secondary diurnal modes of precipitation over oceanic and continental regimes. J. Climate, 21, 4115-4131, https://doi.org/ 10.1175/2008JCLI2140.1.

Yano, J.-I., and M. Bonazzola, 2009: Scale analysis for large-scale tropical atmospheric dynamics. J. Atmos. Sci., 66, 159-172, https://doi.org/10.1175/2008JAS2687.1.

Zängl, G., D. Reinert, P. Rípodas, and M. Baldauf, 2015: The ICON (ICOsahedral Non-hydrostatic) modelling framework of DWD and MPI-M: Description of the nonhydrostatic dynamical core. Quart. J. Roy. Meteor. Soc., 141, 563-579, https://doi.org/10.1002/qj.2378. 